\title{
Resistance of the SoyNAM Parents to Seed and Root Rot Caused by Four Pythium Species
}

\author{
Elizabeth R. Lerch-Olson, ${ }^{1}$ Anne E. Dorrance, ${ }^{2}$ and Alison E. Robertson ${ }^{1, \dagger}$ \\ ${ }^{1}$ Department of Plant Pathology and Microbiology, Iowa State University, Ames, IA 50011 \\ ${ }^{2}$ Department of Plant Pathology, Ohio State University, Wooster, OH 44691
}

\begin{abstract}
Some Pythium spp. cause damping off and root rot in soybeans and other crop species. One of the most effective management tools to reduce disease is host resistance; however, little is known about resistance in soybean to Pythium spp. The soybean nested associated mapping (SoyNAM) parent lines are a set of germplasms that were crossed to a single hub parent to create recombinant inbred line populations for the purpose of mapping ag-

40 SoyNAM parents, only 'Maverick' was resistant to the four species tested; however, 13 were resistant to three species. Other lines were resistant to two, one, or none of the species tested. Correlations between seed and root rot severity for the lines assessed were weak or insignificant. Results indicate that mechanisms of resistance to seed and root rot caused by Pythium spp. may not necessarily be the same.
\end{abstract} ronomic traits. The SoyNAM parents were screened for resistance to Pythium lutarium, Pythium oopapillum, Pythium sylvaticum, and Pythium torulosum in separate assays to evaluate seed and root rot severity. Of the
Keywords: cultivar/resistance, disease management, Pythium, oomycetes, soybean
Seedling diseases are one of the largest contributors to yield loss in soybean (Glycine max [L.] Merr.) production in the United States (Allen et al. 2017; Wrather and Koenning 2006, 2009). From 1996 to 2014 seedling diseases were ranked second to sixth among the diseases contributing to lower soybean yield (Allen et al. 2017; Wrather and Koenning 2009). Pythium spp., along with other pathogens, such as Rhizoctonia solani Kühn, Phytophthora sojae M.J. Kaufmann \& J.W. Gerdemann, and Fusarium spp., cause seedling disease on soybean. The symptoms of seedling disease generally include preemergence and postemergence damping off and root rot (Yang 1999). Seedlings that survive initial infection may still suffer from reduced growth and vigor, leading to reduced yield (Broders et al. 2007). Of the pathogens causing seedling disease on soybean in Iowa, Pythium spp. have been among the most frequently recovered (Murillo-Williams and Pedersen 2008; Yang and Feng 2001). As many as 43 Pythium spp. are known to be pathogenic on soybeans in the North Central region of the United States (Rojas et al. 2017a). In Iowa, Pythium lutarium, Pythium oopapillum, Pythium sylvaticum, and Pythium torulosum were among the eight most abundant pathogenic Pythium spp. recovered from soybeans with seedling disease symptoms (Rojas et al. 2017b).

Management of Pythium spp. can be complex, because they have a wide host range and infect crops typically used in crop rotations in the Midwest, including corn (Broders et al. 2007; Matthiesen et al. 2016; Zhang and Yang 2000). An integrated approach that includes modifying crop production practices and using seed treatments is often necessary. Soybeans are now planted very early in the Midwest, before May 1, if possible, to ensure full yield potential (De Bruin and

${ }^{\dagger}$ Corresponding author: A. E. Robertson; alisonr@iastate.edu

Funding: Partial funding for this research was provided by the United Soybean Board and Hatch Project for Phytobiomes in Crop Health and Disease Management (IOWO3908).@ 2020 The American Phytopathological Society

*The $\boldsymbol{e}$-Xtra logo stands for "electronic extra" and indicates a supplementary table is published online.

The author(s) declare no conflict of interest.

Accepted for publication 10 March 2020.

(c) 2020 The American Phytopathological Society
Pedersen 2008), but this practice often leaves soybean seeds exposed to cool, wet soils that negatively affect seedling development and provide a conducive environment for Pythium spp. infection (Broders et al. 2007; Thomson et al. 1971; Zhang and Yang 2000). Soybean seeds and seedlings may be more susceptible to infection by Pythium spp. under cool, wet conditions (Broders et al. 2007; Thomson et al. 1971; Zhang and Yang 2000). Infested residue of the previous crop left on the soil surface by reduced-tillage practices that are common in the Midwest can also be a source of initial inoculum for the next growing season (Broders et al. 2007). Additionally, crop residue keeps the soil wet and prevents drying, although the high soil moisture can be alleviated by installing tiles or using more conventional tillage practices (Griffith et al. 1977; Van Doren and Triplett 1973).

Seed treatment fungicides, including metalaxyl and mefenoxam, are effective against oomycetes, including Pythium spp. (Yang 1999). However, Dorrance et al. (2004) proposed that the continuous use of metalaxyl and mefenoxam as the sole active ingredients against Pythium spp. selected for insensitive isolates of $P$. catenulatum, $P$. irregulare, $P$. paroecandrum, $P$. splendens, and $P$. torulosum. Most soybean seed treatments include additional fungicide products, including the quinone oxidase inhibitor fungicides azoxystrobin, trifloxystrobin, and pyraclostrobin, which improve the efficacy of the treatment and provide coverage against fungal pathogens (Ellis et al. 2013). However, these additional products are not always effective at inhibiting the growth of all Pythium spp. (Broders et al. 2007; Matthiesen et al. 2016). Additionally, Dorrance et al. (2009) suggested that the efficacy period of the seed treatment is shorter in soybean compared with corn because of epigeal germination, in which the seed coat that is covered with seed treatment is removed from the soil as the seedling emerges.

Host resistance to Pythium spp. is a useful management tool, and it has been observed in many crop host species. Adegbola and Hagedorn (1970) evaluated common bean (Phaseolus vulgaris L.) cultivars for resistance to Pythium debaryanum, Pythium aphanidermatum, and Pythium ultimum with the aim of incorporating resistance into commercial cultivars. More recently, Mahuku et al. (2005) identified a single dominant resistance gene from common bean variety RWR719. In pea (Pisum sativum L.), Ohh et al. (1978) found that some Minnesota breeding lines were more resistant to infection by $P$. ultimum than commercially available cultivars. Variations in resistance to Pythium debaryanum inflatum, which causes stalk rot in corn (Zea mays L.), have also been reported, 
and a dominant resistance gene Rpil was identified (Yang et al. 2005). Johnson and Palmer (1985) found offspring of resistant cotton (Gossypium hirsutum L.) variety Auburn M was resistant to infection by $P$. ultimum. Resistance to $P$. ultimum was identified in periwinkle (Vinca minor L.), variety Nirmal, and was used for more than 15 years (Kulkarni and Baskaran 2003).

In soybean, there are also accounts of resistance to various Pythium spp. (Bates et al. 2008; Ellis et al. 2013; Kirkpatrick et al. 2006; Rod et al. 2018; Rosso et al. 2008). One particular cultivar, Archer, was resistant to multiple species, including P. ultimum, $P$. aphanidermatum, $P$. irregulare, and Pythium vexans, when compared with the cultivar Hutcheson (Bates et al. 2008). A single dominant gene, denoted Rpal, which provided resistance against $P$. aphanidermatum, was identified in 'Archer,' in a population of 'Archer' $\times$ 'Hutcheson' (Rosso et al. 2008). Ellis et al. (2013) evaluated 65 cultivars and plant introductions for resistance to $P$. irregulare and reported that 'PI 424354' was resistant (Dorrance and Schmitthenner 2000). Rod et al. (2018) evaluated 102 ancestors of North American cultivars for resistance to P. ultimum var. ultimum and subsequently screened four of the resistant lines ('Fiskeby III,' 'Fiskeby 840-7-3,' 'Maple Isle,' and 'PI 84637') for resistance to P. irregulare and P. sylvaticum. Additionally, Scott et al. (2019) identified a major quantitative disease resistance locus associated with resistance to $P$. ultimum var. ultimum and $P$. ultimum var. sporangiiferum. Management of Pythium spp. via host resistance could be an effective strategy to reduce losses because of seedling disease.

Numerous assays have been used to identify resistance in various legumes to Pythium. Ohh et al. (1978) used three methods to evaluate pea for resistance to $P$. ultimum, including a lab plate assay to evaluate for pre-emergence damping off, a greenhouse grow-out assay using multiple inoculation methods to determine root rot, and a field trial. Bates et al. (2008) evaluated root discoloration and emergence of soybeans grown in cups filled with soil mix inoculated with $P$. aphanidermatum, Pythium group HS, $P$. irregulare, Pythium oligandrum, $P$. ultimum, and $P$. vexans in greenhouse assays. Similarly, Ellis et al. (2013) and Rod et al. (2018) used a greenhouse cup assay to evaluate for root rot, and Rosso et al. (2008) used a hypocotyl inoculation technique originally developed for Phytophthora sojae, to evaluate the number of plants that survived infection by $P$. aphanidermatum. It is possible that different assays measure resistance that functions at different developmental stages of seed germination and seedling growth, correlating with the different symptoms associated with seedling disease. Pythium infection during seed germination may result in seed rot and pre-emergence damping off, whereas infection during seedling growth results in postemergence damping off or root rot (Pieczarka and Abawi 1978). Rojas et al. (2017a) reported that some Pythium spp. caused more severe seed rot than root rot, whereas others caused more severe root rot and no seed rot. Consequently, different assays may be needed to evaluate for resistance based on the pathogenicity of the species at various stages of germination.

Multiple Pythium spp. are frequently isolated from the same symptomatic seedling (Broders et al. 2007; Dorrance et al. 2004; Rizvi and Yang 1996), indicating that multiple Pythium spp. probably infect soybean as a complex (Rizvi and Yang 1996). Moreover, many species often exist within a single field (Broders et al. 2007; Dorrance et al. 2004). Consequently, identifying resistance to multiple Pythium spp. in soybean may ensure that resistance is a more useful tool to manage soybean seedling disease. Rod et al. (2018), briefly explored resistance to multiple species by evaluating four ancestral soybean lines, resistant to $P$. ultimum var. ultimum, for resistance to $P$. irregulare and $P$. sylvaticum.

The soybean nested association mapping (SoyNAM) parents are a group of 40 soybean cultivars and plant introductions chosen for their wide genetic diversity and high yield (Diers et al. 2011). Each line was crossed to a hub parent, 'IA3023,' to develop 40 populations of 140 recombinant inbred lines (RILs) each. Quantitative trait loci (QTLs) contributing to important agronomic traits have been identified and mapped in each RIL population. The SoyNAM parents and their subsequent populations are available for U.S. researchers to evaluate for other traits of interest in soybean (Diers et al. 2011).
Additionally, the genetic data associated with each of these populations, namely the single nucleotide polymorphism haplotypes, are also available for use at https://soybase.org/SoyNAM. We chose to use this resource to identify resistance to seedling disease caused by various Pythium spp. for the potential of using the SoyNAM RIL populations to map QTLs for resistance to Pythium.

The objectives of this research were to use the SoyNAM parents to identify sources of resistance to $P$. lutarium, $P$. oopapillum, $P$. sylvaticum, and $P$. torulosum; compare resistance assays that evaluate seed rot during seed germination and root rot during seedling growth; and identify SoyNAM parents with resistance to multiple Pythium spp.

\section{Materials and Methods}

Seed source. Seed of the 41 SoyNAM parents (Diers et al. 2011) were obtained from Dr. Jim Specht at the University of Nebraska.

Pythium isolates. Representative isolates of Pythium were obtained from the Robertson lab collection and included $P$. sylvaticum IASO $2-8.18, P$. lutarium IASO 6-2.2r, P. oopapillum IASO 2-11.8, and $P$. torulosum IASO 3-6 (Matthiesen et al. 2016). Isolates were originally collected in a 2012 survey conducted in Iowa and were chosen as representative of that species in Iowa because no differences in the aggressiveness of isolates of the same species were identified (Matthiesen et al. 2016). Isolates were retrieved from long-term storage and transferred to diluted vegetable juice media with antibiotics (DV8++) $\left(40 \mathrm{ml}\right.$ of vegetable juice, $0.6 \mathrm{~g}$ of $\mathrm{CaCO}_{3}$, $0.2 \mathrm{~g}$ of yeast extract, $1 \mathrm{~g}$ of sucrose, $0.01 \mathrm{~g}$ of cholesterol, $20 \mathrm{~g}$ of agar, $1 \mathrm{~L}$ of distilled water, $0.05 \mathrm{~g} /$ /iter of neomycin sulfate, and $0.01 \mathrm{~g} /$ liter of chloramphenicol) modified from Stewart (2011). Isolates were stored in the dark at room temperature $\left(20\right.$ to $\left.22^{\circ} \mathrm{C}\right)$ for 3 to 5 days before being used in the screening assays described below.

Seed rot assay. A modified pathogenicity test by Broders et al. (2007) and Zhang and Yang (2000) was used to evaluate seed rot caused by each Pythium isolate on each of the SoyNAM parents. Each Pythium isolate was transferred to DV8++ on 9-cm Petri plates. The plates were incubated in the dark at $21^{\circ} \mathrm{C}$ for 3 days for $P$. sylvaticum and $P$. lutarium and at $15^{\circ} \mathrm{C}$ for 4 days for $P$. oopapillum and $P$. torulosum, until mycelium colonized the entire plate. These temperatures were optimal for growth of each species, as reported by Matthiesen et al. (2016). Seeds of each line were surface sterilized in a $1 \%$ sodium hypochlorite solution for $3 \mathrm{~min}$, rinsed in sterile water for $3 \mathrm{~min}$, and patted dry on sterilized paper towels. For each line, five seeds were placed on each of four Pythium-colonized plates $(n=$ 40 seeds). To determine germination and as a seed quality control, 10 seeds per line were placed on one noninoculated DV8++ plate. The seeded plates were incubated in the dark for 7 days at $21^{\circ} \mathrm{C}$ for $P$. sylvaticum and $P$. lutarium and at $15^{\circ} \mathrm{C}$ for $P$. oopapillum and $P$. torulosum. Each plate was one replication, with four replications constituting one run of the experiment. There were two experimental runs, arranged in a completely randomized design, for each Pythium species.

To evaluate seed rot, a modified rating scale from Zhang and Yang (2000) was used. The seed rot severity scale was rated from 0 to 4 , where 0 indicated that the seed germinated and there was no radicle discoloration (germination was considered when the radicle was as long as the seed itself), 1 indicated that the seed germinated and < $50 \%$ of the radicle was discolored, 2 indicated that the seed germinated but $>50 \%$ of the radicle was discolored, 3 indicated that the seed had germinated but then rotted, and 4 indicated that the seed rotted without germinating. Seed rot severity was then calculated as an index with the equation:

$$
Y=100 *\left(\sum x_{i} / 20\right)
$$

where $Y$ is the seed rot severity index ( 0 to $100 \%), x_{i}$ is the seed rot severity rating of the $i$ th rep ( $i=1$ to 5), and 20 is the number of seeds per plate times the highest rating. Data were also collected on percentage of rotted seeds and germination.

Root rot assay. Inoculum for the root rot assay was produced via a modified protocol from Matthiesen et al. (2016). Millet was soaked overnight, for at least $12 \mathrm{~h}$, in water and then placed into vented 
autoclavable bags ( $720 \mathrm{ml}$ per bag). The bagged millet was autoclaved twice, with a 24 -h wait period between each autoclave cycle. Millet was inoculated with a 3-day-old culture of Pythium grown on DV8++ media $(10 \mathrm{ml})$. After 3 days of storage at room temperature $\left(20\right.$ to $22^{\circ} \mathrm{C}$ ), the bags were mixed thoroughly every day by being gently turned over several times. The Pythium isolate was allowed to colonize the millet for 10 to 14 days and was used immediately.

For assay preparation, $5 \mathrm{ml}$ of Pythium-infested millet was placed in a layer approximately $2 \mathrm{~cm}$ below the seed surface in a $237-\mathrm{ml}$ (8-oz.) polystyrene cup. First, $72 \mathrm{ml}$ of sterile sand-soil mix $(2: 1)$ was placed in the cup, and an inoculum layer was placed immediately on top and covered with $30 \mathrm{ml}$ of sterile sand-soil mix. The seeds were placed on top of the sand-soil mix, and thus the seed was separated from the inoculum, and finally a $30 \mathrm{ml}$ layer of vermiculite was placed on top of the seeds. Five seeds were placed in each of two treatment cups ( $N=20$ seeds). Two cups were also planted without inoculum as a control. The cups were incubated for 2 weeks at $21^{\circ} \mathrm{C}$ for $P$. lutarium and $P$. sylvaticum. For cups inoculated with
P. oopapillum and $P$. torulosum, incubation was done at $18^{\circ} \mathrm{C}$ for 3 weeks. Each treatment cup was one replication, and two replications were done in each run of an experiment. There were two runs per experiment, arranged in a completely randomized design, for each of the four Pythium spp.

Root rot severity was assessed on a 0 to 4 rating scale (Wickramasinghe et al. 2012), where 0 indicated that the roots were long and full, with no signs of discoloration or infection by the pathogen and similar to roots of the noninoculated control plants; 1 indicated that the roots were slightly stunted and mildly discolored; 2 indicated that the roots were severely stunted and may be severely discolored; 3 indicated that the roots were very short and rotted; and a 4 indicated a nonemerged, dead seedling. Root rot severity was then calculated as an index with the equation:

$$
Y=100 *\left(\sum x_{i} / 20\right)
$$

where $Y$ is the root rot severity index ( 0 to $100 \%), x_{i}$ is the root rot severity rating of the $i$ th rep $(i=1$ to 5$)$, and 20 is the number of

Table 1. Resistance assessments of 40 SoyNAM parents to Pythium lutarium in seed and root rot assays ${ }^{\mathrm{z}}$

\begin{tabular}{|c|c|c|c|c|c|c|}
\hline \multirow[b]{2}{*}{ NAM parent } & \multicolumn{3}{|c|}{ Seed rot assay } & \multicolumn{3}{|c|}{ Root rot assay } \\
\hline & $\begin{array}{l}\text { Seed rot severity } \\
(\%)\end{array}$ & $\begin{array}{l}\text { Rotted seeds } \\
(\%)\end{array}$ & $\begin{array}{c}\text { Germination } \\
(\%)\end{array}$ & $\begin{array}{c}\text { Root rot severity } \\
(\%)\end{array}$ & $\begin{array}{c}\text { Adjusted dry root weight } \\
(\%)\end{array}$ & $\begin{array}{c}\text { Adjusted emergence } \\
(\%)\end{array}$ \\
\hline $4 \mathrm{~J} 105-3-4$ & $35.3 \mathrm{e}-\mathrm{k}$ & $2.5 \mathrm{fg}$ & $95.0 \mathrm{ab}$ & $44.4 \mathrm{e}-\mathrm{g}$ & 56.2 & $95.0 \mathrm{a}-\mathrm{c}$ \\
\hline $5 \mathrm{M} 20-2-5-2$ & $36.9 \mathrm{~d}-\mathrm{j}$ & $10.0 \mathrm{c}-\mathrm{f}$ & $90.0 \mathrm{~b}-\mathrm{d}$ & $63.8 \mathrm{a}-\mathrm{e}$ & 98.0 & $84.0 \mathrm{a}-\mathrm{c}$ \\
\hline CL0J095-4-6 & $44.4 \mathrm{~b}-\mathrm{d}$ & $12.5 \mathrm{~b}-\mathrm{e}$ & $90.0 \mathrm{~b}-\mathrm{d}$ & $51.9 \mathrm{c}-\mathrm{g}$ & 74.7 & $85.0 \mathrm{a}-\mathrm{c}$ \\
\hline CL0J173-6-8 & $34.4 \mathrm{e}-\mathrm{k}$ & $2.5 \mathrm{fg}$ & $97.5 \mathrm{ab}$ & $36.3 \mathrm{~g}$ & 81.9 & $100.0 \mathrm{ab}$ \\
\hline HS6-3976 & $38.1 \mathrm{~d}-\mathrm{i}$ & $0.0 \mathrm{~g}$ & $100.0 \mathrm{a}$ & $44.4 \mathrm{e}-\mathrm{g}$ & 58.9 & $105.0 \mathrm{a}$ \\
\hline IA3023 & $34.4 \mathrm{e}-\mathrm{k}$ & $0.0 \mathrm{~g}$ & $100.0 \mathrm{a}$ & $61.3 \mathrm{a}-\mathrm{e}$ & 76.1 & $94.5 \mathrm{a}-\mathrm{c}$ \\
\hline LD00-3309 & $41.3 \mathrm{~d}-\mathrm{f}$ & $2.5 \mathrm{fg}$ & $100.0 \mathrm{a}$ & $58.1 \mathrm{c}-\mathrm{f}$ & 66.5 & $75.0 \mathrm{~b}-\mathrm{d}$ \\
\hline LD01-5907 & $33.8 \mathrm{f}-\mathrm{k}$ & $5.0 \mathrm{e}-\mathrm{g}$ & $95.0 \mathrm{ab}$ & $52.5 \mathrm{c}-\mathrm{g}$ & 61.1 & $105.5 \mathrm{a}$ \\
\hline LD02-4485 & $38.9 \mathrm{~d}-\mathrm{g}$ & $10.0 \mathrm{c}-\mathrm{f}$ & $90.0 \mathrm{~b}-\mathrm{d}$ & $53.8 \mathrm{c}-\mathrm{g}$ & 64.8 & $100.0 \mathrm{ab}$ \\
\hline LD02-9050 & $33.8 \mathrm{f}-\mathrm{k}$ & $0.0 \mathrm{~g}$ & $100.0 \mathrm{a}$ & $43.8 \mathrm{e}-\mathrm{g}$ & 72.8 & $90.0 \mathrm{a}-\mathrm{c}$ \\
\hline LG00-3372 & $35.0 \mathrm{e}-\mathrm{k}$ & $0.0 \mathrm{~g}$ & $100.0 \mathrm{a}$ & $38.1 \mathrm{fg}$ & 81.4 & $100.0 \mathrm{ab}$ \\
\hline LG03-2979 & $37.5 \mathrm{~d}-\mathrm{i}$ & $0.0 \mathrm{~g}$ & $100.0 \mathrm{a}$ & $58.1 \mathrm{c}-\mathrm{f}$ & 97.2 & $99.8 \mathrm{ab}$ \\
\hline LG03-3191 & $34.4 \mathrm{e}-\mathrm{k}$ & $0.0 \mathrm{~g}$ & $100.0 \mathrm{a}$ & $60.6 \mathrm{~b}-\mathrm{e}$ & 70.6 & $72.3 \mathrm{~cd}$ \\
\hline LG04-4717 & $34.4 \mathrm{e}-\mathrm{k}$ & $2.5 \mathrm{fg}$ & $97.5 \mathrm{ab}$ & $50.6 \mathrm{~d}-\mathrm{g}$ & 103.2 & $94.5 \mathrm{a}-\mathrm{c}$ \\
\hline LG04-6000 & $35.6 \mathrm{e}-\mathrm{k}$ & $5.0 \mathrm{e}-\mathrm{g}$ & $95.0 \mathrm{ab}$ & $46.9 \mathrm{~d}-\mathrm{g}$ & 85.7 & $100.0 \mathrm{ab}$ \\
\hline LG05-4292 & $41.3 \mathrm{~d}-\mathrm{f}$ & $0.0 \mathrm{~g}$ & $100.0 \mathrm{a}$ & $56.9 \mathrm{c}-\mathrm{g}$ & 76.7 & $70.0 \mathrm{c}-\mathrm{e}$ \\
\hline LG05-4317 & $41.9 \mathrm{c}-\mathrm{e}$ & $20.0 \mathrm{~b}$ & $80.0 \mathrm{e}$ & $63.1 \mathrm{a}-\mathrm{e}$ & 61.2 & $85.0 \mathrm{a}-\mathrm{c}$ \\
\hline LG05-4464 & $25.0 \mathrm{~lm}$ & $2.5 \mathrm{fg}$ & $97.5 \mathrm{ab}$ & $58.1 \mathrm{c}-\mathrm{f}$ & 66.7 & $105.0 \mathrm{a}$ \\
\hline LG05-4832 & $34.4 \mathrm{e}-\mathrm{k}$ & $2.5 \mathrm{fg}$ & $97.5 \mathrm{ab}$ & $38.8 \mathrm{fg}$ & 81.3 & $100.0 \mathrm{ab}$ \\
\hline LG90-2550 & $31.3 \mathrm{~h}-1$ & $2.5 \mathrm{fg}$ & $97.5 \mathrm{ab}$ & $53.1 \mathrm{c}-\mathrm{g}$ & 75.4 & $105.5 \mathrm{a}$ \\
\hline LG92-1255 & $28.8 \mathrm{kl}$ & $0.0 \mathrm{~g}$ & $100.0 \mathrm{a}$ & $53.8 \mathrm{c}-\mathrm{g}$ & 77.4 & $99.8 \mathrm{ab}$ \\
\hline LG94-1128 & $31.3 \mathrm{~h}-1$ & $5.0 \mathrm{e}-\mathrm{g}$ & $95.0 \mathrm{ab}$ & $52.5 \mathrm{c}-\mathrm{g}$ & 82.5 & $105.5 \mathrm{a}$ \\
\hline LG94-1906 & $25.5 \mathrm{~lm}$ & $5.0 \mathrm{e}-\mathrm{g}$ & $92.5 \mathrm{a}-\mathrm{c}$ & $54.4 \mathrm{c}-\mathrm{g}$ & 53.0 & $89.3 \mathrm{a}-\mathrm{c}$ \\
\hline LG97-7012 & $63.8 \mathrm{a}$ & $52.5 \mathrm{a}$ & $50.0 \mathrm{f}$ & $46.3 \mathrm{~d}-\mathrm{g}$ & 87.1 & $106.0 \mathrm{a}$ \\
\hline LG98-1605 & $38.8 \mathrm{~d}-\mathrm{h}$ & $2.5 \mathrm{fg}$ & $97.5 \mathrm{ab}$ & $61.3 \mathrm{a}-\mathrm{e}$ & 62.7 & $75.0 \mathrm{~b}-\mathrm{d}$ \\
\hline Magellan & $31.9 \mathrm{~g}-1$ & $0.0 \mathrm{~g}$ & $100.0 \mathrm{a}$ & $46.9 \mathrm{~d}-\mathrm{g}$ & 92.9 & $94.5 \mathrm{a}-\mathrm{c}$ \\
\hline Maverick & $30.6 \mathrm{i}-1$ & $0.0 \mathrm{~g}$ & $100.0 \mathrm{a}$ & $44.4 \mathrm{e}-\mathrm{g}$ & 59.7 & $99.8 \mathrm{ab}$ \\
\hline NE3001 & $35.0 \mathrm{e}-\mathrm{k}$ & $2.5 \mathrm{fg}$ & $97.5 \mathrm{ab}$ & $46.9 \mathrm{~d}-\mathrm{g}$ & 72.8 & $105.0 \mathrm{a}$ \\
\hline PI 398.881 & $41.9 \mathrm{c}-\mathrm{e}$ & $7.5 \mathrm{~d}-\mathrm{g}$ & $92.5 \mathrm{a}-\mathrm{c}$ & $66.3 \mathrm{a}-\mathrm{d}$ & 66.8 & $84.0 \mathrm{a}-\mathrm{c}$ \\
\hline PI 404.188A & $37.3 \mathrm{~d}-\mathrm{i}$ & $12.5 \mathrm{~b}-\mathrm{e}$ & $85.0 \mathrm{c}-\mathrm{e}$ & $80.0 \mathrm{ab}$ & 65.9 & $57.8 \mathrm{de}$ \\
\hline PI 427.136 & $31.9 \mathrm{~g}-1$ & $10.0 \mathrm{c}-\mathrm{f}$ & $90.0 \mathrm{~b}-\mathrm{d}$ & 59.4 b-f & 77.0 & $81.3 \mathrm{a}-\mathrm{d}$ \\
\hline PI 437.169B & $36.9 \mathrm{~d}-\mathrm{j}$ & $5.0 \mathrm{e}-\mathrm{g}$ & $95.0 \mathrm{ab}$ & $43.8 \mathrm{e}-\mathrm{g}$ & 71.9 & $95.0 \mathrm{a}-\mathrm{c}$ \\
\hline PI 507.681B & $29.4 \mathrm{j}-1$ & $10.0 \mathrm{c}-\mathrm{f}$ & $90.0 \mathrm{~b}-\mathrm{d}$ & $56.3 \mathrm{c}-\mathrm{g}$ & 72.7 & $94.5 \mathrm{a}-\mathrm{c}$ \\
\hline PI 518.751 & $20.6 \mathrm{~m}$ & $5.0 \mathrm{e}-\mathrm{g}$ & $92.5 \mathrm{a}-\mathrm{c}$ & $57.5 \mathrm{c}-\mathrm{g}$ & 84.8 & $90.0 \mathrm{a}-\mathrm{c}$ \\
\hline PI 561.370 & $38.1 \mathrm{~d}-\mathrm{i}$ & $15.0 \mathrm{~b}-\mathrm{d}$ & $92.5 \mathrm{a}-\mathrm{c}$ & $60.6 \mathrm{~b}-\mathrm{e}$ & 63.7 & $84.0 \mathrm{a}-\mathrm{c}$ \\
\hline PI 574.486 & $40.0 \mathrm{~d}-\mathrm{f}$ & $15.0 \mathrm{~b}-\mathrm{d}$ & $85.0 \mathrm{c}-\mathrm{e}$ & $72.5 \mathrm{a}-\mathrm{c}$ & 94.7 & $88.5 \mathrm{a}-\mathrm{c}$ \\
\hline Prohio & $38.0 \mathrm{~d}-\mathrm{i}$ & $5.0 \mathrm{e}-\mathrm{g}$ & $92.5 \mathrm{a}-\mathrm{c}$ & $52.5 \mathrm{c}-\mathrm{g}$ & 61.4 & $94.5 \mathrm{a}-\mathrm{c}$ \\
\hline S06-13640 & $49.4 \mathrm{bc}$ & $15.0 \mathrm{~b}-\mathrm{d}$ & $85.0 \mathrm{c}-\mathrm{e}$ & $46.3 \mathrm{~d}-\mathrm{g}$ & 72.8 & $94.5 \mathrm{a}-\mathrm{c}$ \\
\hline Skylla & $37.7 \mathrm{~d}-\mathrm{i}$ & $7.5 \mathrm{e}-\mathrm{g}$ & $95.0 \mathrm{ab}$ & $55.6 \mathrm{c}-\mathrm{g}$ & 64.1 & $105.5 \mathrm{a}$ \\
\hline TN05-3027 & $50.0 \mathrm{~b}$ & $17.5 \mathrm{bc}$ & $82.5 \mathrm{de}$ & $57.5 \mathrm{c}-\mathrm{g}$ & 61.6 & $89.0 \mathrm{a}-\mathrm{c}$ \\
\hline U03-100612 & $31.1 \mathrm{i}-1$ & $2.5 \mathrm{fg}$ & $95.0 \mathrm{ab}$ & $55.6 \mathrm{c}-\mathrm{g}$ & 58.2 & $94.5 \mathrm{a}-\mathrm{c}$ \\
\hline Archer & $39.7 \mathrm{~d}-\mathrm{f}$ & $2.5 \mathrm{fg}$ & $97.5 \mathrm{ab}$ & $53.1 \mathrm{c}-\mathrm{g}$ & 81.9 & $106.0 \mathrm{a}$ \\
\hline Sloan & $51.9 \mathrm{~b}$ & $12.5 \mathrm{~b}-\mathrm{e}$ & $92.5 \mathrm{a}-\mathrm{c}$ & $82.5 \mathrm{a}$ & 43.2 & $44.5 \mathrm{e}$ \\
\hline$P$ & $<0.0001$ & $<0.0001$ & $<0.0001$ & 0.0182 & 0.0612 & 0.0006 \\
\hline
\end{tabular}

${ }^{\mathrm{z}}$ Lowercase letters indicate significant differences between parents within a column. 
planted seedlings per cup times the highest rating. Dry root weight and emergence were also recorded. Dry root weight per cup was adjusted to the nontreated control as follows:

Adjusted dry root weight $=($ Average dry root weight per root of emerged, inoculated seedlings/Average dry root weight per root of emerged noninoculated seedlings) $* 100$

Similarly, emergence was adjusted as follows:

Adjusted emergence $=($ number of emerged seedlings in inoculated cups/Average number of emerged seedlings in noninoculated cups $) * 100$

Data analyses. Analysis of variance (ANOVA) was used to determine significant differences between runs in the checks ('Archer' and
'Sloan') of each experiment. No significant differences $(P>0.05)$ in run were found, and therefore data were combined for subsequent analyses. ANOVA was performed with the fit model function and was used to determine significant differences between the lines for all measured variables. Additionally, germination and emergence of controls were tested for differences between lines (Supplementary Table 1). Where significant differences between lines were detected, Student's $t(P<$ $0.05)$ was used for comparison. Pairwise correlation analysis, with the multivariate methods function, was used to determine whether there was a relationship between seed rot severity, rotted seeds, and germination for each species, as well as between root rot severity, adjusted dry root weight, and adjusted emergence. Additionally, it was used to identify relationships between seed rot and root rot severity within a species and a relationship between seed rot severity and root rot severity between Pythium spp. All analyses were performed in JMP Pro 14.3.

For the purposes of this research, a parent was considered to be resistant to seed rot or root rot caused by a particular Pythium

Table 2. Resistance assessments of the 40 SoyNAM parents to Pythium oopapillum in seed and root rot assays ${ }^{\mathrm{z}}$

\begin{tabular}{|c|c|c|c|c|c|c|}
\hline \multirow[b]{2}{*}{$\begin{array}{l}\text { NAM } \\
\text { parent }\end{array}$} & \multicolumn{3}{|c|}{ Seed rot assay } & \multicolumn{3}{|c|}{ Root rot assay } \\
\hline & $\begin{array}{c}\text { Seed rot severity } \\
(\%)\end{array}$ & $\begin{array}{c}\text { Rotted seeds } \\
(\%)\end{array}$ & $\begin{array}{c}\text { Germination } \\
(\%)\end{array}$ & $\begin{array}{c}\text { Root rot severity } \\
(\%)\end{array}$ & $\begin{array}{c}\text { Adjusted dry root weight } \\
(\%)\end{array}$ & $\begin{array}{c}\text { Adjusted emergence } \\
(\%)\end{array}$ \\
\hline $4 \mathrm{~J} 105-3-4$ & $60.6 \mathrm{~b}-\mathrm{e}$ & $27.5 \mathrm{~d}-\mathrm{h}$ & $77.5 \mathrm{c}-\mathrm{g}$ & $65.6 j-p$ & 43.8 & $75.0 \mathrm{a}-\mathrm{g}$ \\
\hline $5 \mathrm{M} 20-2-5-2$ & $51.3 \mathrm{~g}-1$ & $30.0 \mathrm{c}-\mathrm{g}$ & $80.0 \mathrm{~b}-\mathrm{f}$ & $85.0 \mathrm{a}-\mathrm{c}$ & 45.2 & $37.5 \mathrm{j}-\mathrm{n}$ \\
\hline CL0J095-4-6 & $56.9 \mathrm{~d}-\mathrm{g}$ & $22.5 \mathrm{e}-\mathrm{j}$ & $87.5 \mathrm{a}-\mathrm{c}$ & $66.3 \mathrm{i}-\mathrm{p}$ & 51.8 & $82.8 \mathrm{a}-\mathrm{d}$ \\
\hline CL0J173-6-8 & $51.3 \mathrm{~g}-1$ & $20.0 \mathrm{f}-\mathrm{k}$ & $82.5 \mathrm{a}-\mathrm{e}$ & $73.8 \mathrm{e}-\mathrm{k}$ & 47.3 & $81.4 \mathrm{a}-\mathrm{e}$ \\
\hline HS6-3976 & $48.1 \mathrm{i}-\mathrm{n}$ & $15.0 \mathrm{~h}-1$ & $90.0 \mathrm{a}-\mathrm{c}$ & 79.4 b-f & 54.7 & $52.7 \mathrm{f}-1$ \\
\hline IA 3023 & $69.4 \mathrm{a}$ & $47.5 \mathrm{ab}$ & $57.5 \mathrm{i}$ & $80.6 \mathrm{~b}-\mathrm{f}$ & 43.9 & $57.9 \mathrm{~d}-1$ \\
\hline LD00-3309 & $60.0 \mathrm{c}-\mathrm{f}$ & $35.0 \mathrm{~b}-\mathrm{e}$ & $72.5 \mathrm{~d}-\mathrm{h}$ & $65.0 \mathrm{k}-\mathrm{q}$ & 64.2 & $59.0 \mathrm{~d}-1$ \\
\hline LD01-5907 & $56.3 \mathrm{~d}-\mathrm{h}$ & $30.0 \mathrm{c}-\mathrm{g}$ & $70.0 \mathrm{e}-\mathrm{i}$ & $78.1 \mathrm{~b}-\mathrm{g}$ & 69.8 & $50.0 \mathrm{~g}-1$ \\
\hline LD02-4485 & $44.41-\mathrm{q}$ & $25.0 \mathrm{e}-\mathrm{i}$ & $85.0 \mathrm{a}-\mathrm{d}$ & $61.3 \mathrm{~m}-\mathrm{s}$ & 49.2 & $75.0 \mathrm{a}-\mathrm{g}$ \\
\hline LD02-9050 & $55.0 \mathrm{~d}-\mathrm{i}$ & $22.5 \mathrm{e}-\mathrm{j}$ & $80.0 \mathrm{~b}-\mathrm{f}$ & $68.8 \mathrm{~h}-\mathrm{n}$ & 39.2 & $62.1 \mathrm{c}-\mathrm{k}$ \\
\hline LG00-3372 & $48.8 \mathrm{i}-\mathrm{n}$ & $20.0 \mathrm{e}-\mathrm{k}$ & $80.0 \mathrm{~b}-\mathrm{f}$ & $66.9 \mathrm{i}-\mathrm{p}$ & 43.5 & $73.7 \mathrm{a}-\mathrm{g}$ \\
\hline LG03-2979 & $35.6 \mathrm{r}$ & $15.0 \mathrm{~h}-1$ & $85.0 \mathrm{a}-\mathrm{d}$ & $75.0 \mathrm{~d}-\mathrm{i}$ & 43.9 & $56.9 \mathrm{e}-1$ \\
\hline LG03-3191 & $54.4 \mathrm{e}-\mathrm{i}$ & $25.0 \mathrm{e}-\mathrm{i}$ & $80.0 \mathrm{~b}-\mathrm{f}$ & $60.0 \mathrm{n}-\mathrm{s}$ & 50.1 & $71.0 \mathrm{a}-\mathrm{h}$ \\
\hline LG04-4717 & $44.41-\mathrm{q}$ & $15.0 \mathrm{~h}-1$ & $90.0 \mathrm{a}-\mathrm{c}$ & $58.8 \mathrm{o}-\mathrm{s}$ & 39.8 & $86.5 \mathrm{a}-\mathrm{c}$ \\
\hline LG04-6000 & $45.0 \mathrm{k}-\mathrm{p}$ & $17.5 \mathrm{~g}-1$ & $85.0 \mathrm{a}-\mathrm{d}$ & $72.5 \mathrm{f}-\mathrm{k}$ & 46.6 & $60.0 \mathrm{~d}-1$ \\
\hline LG05-4292 & $52.9 \mathrm{f}-\mathrm{j}$ & $22.5 \mathrm{e}-\mathrm{j}$ & $82.5 \mathrm{a}-\mathrm{e}$ & $58.8 \mathrm{o}-\mathrm{s}$ & 46.2 & $77.6 \mathrm{a}-\mathrm{f}$ \\
\hline LG05-4317 & $65.0 \mathrm{a}-\mathrm{c}$ & $40.0 \mathrm{a}-\mathrm{d}$ & $72.5 \mathrm{~d}-\mathrm{h}$ & $86.9 \mathrm{ab}$ & 61.1 & $36.9 \mathrm{k}-\mathrm{n}$ \\
\hline LG05-4464 & $59.9 \mathrm{c}-\mathrm{f}$ & $32.5 \mathrm{c}-\mathrm{f}$ & $67.5 \mathrm{f}-\mathrm{i}$ & $63.11-\mathrm{r}$ & 31.4 & $73.7 \mathrm{a}-\mathrm{g}$ \\
\hline LG05-4832 & $49.4 \mathrm{~h}-\mathrm{m}$ & $25.0 \mathrm{e}-\mathrm{i}$ & $82.5 \mathrm{a}-\mathrm{e}$ & 49.4 tu & 51.1 & $94.8 \mathrm{a}$ \\
\hline LG90-2550 & 39.6 o-r & $7.5 \mathrm{kl}$ & $87.5 \mathrm{a}-\mathrm{c}$ & $48.1 \mathrm{u}$ & 54.6 & $82.8 \mathrm{a}-\mathrm{d}$ \\
\hline LG92-1255 & $37.5 \mathrm{qr}$ & $17.5 \mathrm{~g}-1$ & $82.5 \mathrm{a}-\mathrm{e}$ & $70.0 \mathrm{~g}-\mathrm{m}$ & 43.0 & $66.1 \mathrm{c}-\mathrm{h}$ \\
\hline LG94-1128 & $39.4 \mathrm{p}-\mathrm{r}$ & $7.5 \mathrm{kl}$ & $92.5 \mathrm{ab}$ & $66.3 \mathrm{i}-\mathrm{p}$ & 55.3 & $68.4 \mathrm{~b}-\mathrm{h}$ \\
\hline LG94-1906 & $43.1 \mathrm{~m}-\mathrm{q}$ & $12.5 \mathrm{i}-1$ & $92.5 \mathrm{ab}$ & $91.9 \mathrm{a}$ & 41.3 & $21.4 \mathrm{mn}$ \\
\hline LG97-7012 & $45.6 \mathrm{j}-\mathrm{p}$ & $20.0 \mathrm{f}-\mathrm{k}$ & $82.5 \mathrm{a}-\mathrm{e}$ & $83.8 \mathrm{a}-\mathrm{d}$ & 105.3 & $39.6 \mathrm{i}-\mathrm{n}$ \\
\hline LG98-1605 & $40.6 \mathrm{o}-\mathrm{r}$ & 5.01 & $95.0 \mathrm{a}$ & $91.9 \mathrm{a}$ & 73.6 & $16.1 \mathrm{n}$ \\
\hline Magellan & $46.3 \mathrm{j}-\mathrm{p}$ & $15.0 \mathrm{~h}-1$ & $92.5 \mathrm{ab}$ & $77.5 \mathrm{c}-\mathrm{h}$ & 45.0 & $46.6 \mathrm{~h}-\mathrm{m}$ \\
\hline Maverick & $41.9 \mathrm{n}-\mathrm{r}$ & $12.5 \mathrm{i}-1$ & $87.5 \mathrm{a}-\mathrm{c}$ & $58.1 \mathrm{p}-\mathrm{t}$ & 56.4 & $82.8 \mathrm{a}-\mathrm{d}$ \\
\hline NE3001 & $46.9 \mathrm{j}-\mathrm{o}$ & $25.0 \mathrm{e}-\mathrm{i}$ & $82.5 \mathrm{a}-\mathrm{e}$ & $56.3 \mathrm{q}-\mathrm{u}$ & 56.3 & $81.9 \mathrm{a}-\mathrm{e}$ \\
\hline PI 398.881 & $51.8 \mathrm{~g}-1$ & $30.0 \mathrm{c}-\mathrm{g}$ & $65.0 \mathrm{~g}-\mathrm{i}$ & $48.8 \mathrm{u}$ & 49.4 & $75.0 \mathrm{a}-\mathrm{g}$ \\
\hline PI 404.188A & $54.9 \mathrm{~d}-\mathrm{i}$ & $35.0 \mathrm{~b}-\mathrm{e}$ & $70.0 \mathrm{e}-\mathrm{i}$ & $75.0 \mathrm{~d}-\mathrm{i}$ & 46.6 & $66.7 \mathrm{c}-\mathrm{h}$ \\
\hline PI 427.136 & $44.41-\mathrm{q}$ & $20.0 \mathrm{f}-\mathrm{k}$ & $85.0 \mathrm{a}-\mathrm{d}$ & $70.0 \mathrm{~g}-\mathrm{m}$ & 47.5 & $57.7 \mathrm{~d}-1$ \\
\hline PI 437.169B & $58.5 \mathrm{c}-\mathrm{g}$ & $35.0 \mathrm{~b}-\mathrm{e}$ & $67.5 \mathrm{f}-\mathrm{i}$ & $67.5 \mathrm{i}-\mathrm{o}$ & 61.4 & $51.0 \mathrm{~g}-1$ \\
\hline PI 507.681B & $54.4 \mathrm{e}-\mathrm{i}$ & $25.0 \mathrm{e}-\mathrm{i}$ & $82.5 \mathrm{a}-\mathrm{e}$ & $80.0 \mathrm{~b}-\mathrm{f}$ & 42.1 & $47.4 \mathrm{~h}-1$ \\
\hline PI 518.751 & $51.3 \mathrm{~g}-1$ & $25.0 \mathrm{e}-\mathrm{i}$ & $85.0 \mathrm{a}-\mathrm{d}$ & $52.5 \mathrm{~s}-\mathrm{u}$ & 50.9 & $93.1 \mathrm{ab}$ \\
\hline PI 561.370 & $61.9 \mathrm{~b}-\mathrm{d}$ & $40.0 \mathrm{a}-\mathrm{d}$ & $70.0 \mathrm{e}-\mathrm{i}$ & $70.0 \mathrm{~g}-\mathrm{m}$ & 42.7 & $60.0 \mathrm{~d}-1$ \\
\hline PI 574.486 & $67.5 \mathrm{ab}$ & $52.5 \mathrm{a}$ & $65.0 \mathrm{~g}-\mathrm{i}$ & $78.1 \mathrm{~b}-\mathrm{g}$ & 58.6 & $67.9 \mathrm{~b}-\mathrm{h}$ \\
\hline Prohio & $65.0 \mathrm{a}-\mathrm{c}$ & $42.5 \mathrm{a}-\mathrm{c}$ & $60.0 \mathrm{hi}$ & $71.9 \mathrm{f}-1$ & 45.9 & $81.4 \mathrm{a}-\mathrm{e}$ \\
\hline S06-13640 & $57.5 \mathrm{~d}-\mathrm{g}$ & $25.0 \mathrm{e}-\mathrm{i}$ & $80.0 \mathrm{~b}-\mathrm{f}$ & $78.8 \mathrm{~b}-\mathrm{g}$ & 81.3 & $34.61-n$ \\
\hline Skylla & $62.3 \mathrm{a}-\mathrm{d}$ & $40.0 \mathrm{a}-\mathrm{d}$ & $70.0 \mathrm{e}-\mathrm{i}$ & $76.9 \mathrm{c}-\mathrm{h}$ & 51.7 & $54.6 \mathrm{f}-1$ \\
\hline TN05-3027 & $67.5 \mathrm{ab}$ & $40.0 \mathrm{a}-\mathrm{d}$ & $65.0 \mathrm{~g}-\mathrm{i}$ & $81.9 \mathrm{~b}-\mathrm{e}$ & 39.5 & $64.7 \mathrm{c}-\mathrm{i}$ \\
\hline U03-100612 & $37.4 \mathrm{qr}$ & $15.0 \mathrm{~h}-1$ & $80.0 \mathrm{~b}-\mathrm{f}$ & $70.0 \mathrm{~g}-\mathrm{m}$ & 46.1 & $57.9 \mathrm{~d}-1$ \\
\hline Archer & $40.1 \mathrm{o}-\mathrm{r}$ & $10.0 \mathrm{j}-1$ & $87.5 \mathrm{a}-\mathrm{c}$ & $55.0 \mathrm{r}-\mathrm{u}$ & 53.7 & $96.2 \mathrm{a}$ \\
\hline Sloan & $51.9 \mathrm{~g}-\mathrm{k}$ & $12.5 \mathrm{i}-1$ & $92.5 \mathrm{ab}$ & $74.4 \mathrm{e}-\mathrm{j}$ & 51.1 & $62.5 \mathrm{c}-\mathrm{j}$ \\
\hline$P$ & $<0.0001$ & 0.0001 & 0.0001 & $<0.0001$ & 0.5649 & $<0.0001$ \\
\hline
\end{tabular}

${ }^{\mathrm{z}}$ Lowercase letters indicate significant differences between parents within a column. 
species when the parent had a significantly lower severity score compared with 'Sloan,' the susceptible check $(P \leq 0.05)$ in either assay. The cultivar Sloan was chosen because of previous work by Broders et al. (2007) and Matthiesen et al. (2016) identifying it as susceptible to multiple Pythium spp. To be considered resistant to a particular Pythium species, the parent had to be significantly different from 'Sloan' in both disease assays $(P \leq 0.05)$ because both assays measured different parameters that contribute to resistance.

\section{Results}

Resistance to seed rot. Seed rot severity among all of the SoyNAM parents varied for $P$. lutarium (Table 1), $P$. oopapillum (Table 2), P. sylvaticum (Table 3), and P. torulosum (Table 4); it ranged from 20.6 to $63.8 \%, 35.6$ to $69.4 \%, 56.9$ to $93.1 \%$, and 22.5 to $55.6 \%$, respectively. Similarly, the average percentage of rotted seeds and average germination varied between species. Rotted seeds ranged from 0 to $52.5 \%, 5$ to $52.5 \%, 27.5$ to $97.5 \%$, and 0 to $25 \%$ and germination ranged from 80 to $100 \%, 57.5$ to $95 \%, 20$ to $80 \%$, and 75 to $100 \%$ for P. lutarium, P. oopapillum, P. sylvaticum, and $P$. torulosum, respectively. The seed rot severity of 'Sloan' ranged from 45 to $90 \%$ depending on the species being tested. Six of the parents, 'LG03-2979,' 'LG90-2550,' 'LG94-1128,' 'LG941906,' 'Maverick,' and 'U03-100612,' had significantly less seed rot than 'Sloan' to all four Pythium spp. tested in the seed rot assay. Of the remaining parents, 18 were resistant to three species tested, 11 to two species tested, 5 to one of the species tested, and 1 to none of the species tested. The hub parent of the SoyNAM populations, 'IA 3023,' had significantly less seed rot caused by P. lutarium, more seed rot caused by $P$. oopapillum, similar seed rot severity caused by $P$. sylvaticum, and less seed rot caused by $P$. torulosum than 'Sloan.'

Resistance to root rot. Root rot severity, adjusted dry root weight, and adjusted emergence varied between all SoyNAM parents for each of the species tested. However, there was no significant difference between parents for adjusted dry root weight. Root rot severity ranged from 36.3 to $80 \%, 48.1$ to $91.9 \%, 33.1$ to $77.5 \%$, and 17.5 to $70 \%$; adjusted dry root weight ranged from 53 to $103.2 \%, 31.4$ to $105.3 \%, 48.1$ to $87.7 \%$, and 48.7 to $99.2 \%$; and adjusted emergence

Table 3. Resistance assessments of the 40 SoyNAM parents to Pythium sylvaticum in seed and root rot assays ${ }^{\mathrm{z}}$

\begin{tabular}{|c|c|c|c|c|c|c|}
\hline \multirow[b]{2}{*}{ NAM parent } & \multicolumn{3}{|c|}{ Seed rot assay } & \multicolumn{3}{|c|}{ Root rot assay } \\
\hline & $\begin{array}{c}\text { Seed rot severity } \\
(\%)\end{array}$ & $\begin{array}{c}\text { Rotted seeds } \\
(\%)\end{array}$ & $\begin{array}{c}\text { Germination } \\
(\%)\end{array}$ & $\begin{array}{c}\text { Root rot severity } \\
(\%)\end{array}$ & $\begin{array}{c}\text { Adjusted dry root weight } \\
(\%)\end{array}$ & $\begin{array}{c}\text { Adjusted emergence } \\
(\%)\end{array}$ \\
\hline $4 \mathrm{~J} 105-3-4$ & $63.8 \mathrm{i}-\mathrm{n}$ & $35.0 \mathrm{mn}$ & $72.5 \mathrm{a}-\mathrm{d}$ & $63.1 \mathrm{a}-\mathrm{j}$ & 70.3 & $94.5 \mathrm{a}-\mathrm{e}$ \\
\hline $5 \mathrm{M} 20-2-5-2$ & $80.0 \mathrm{c}-\mathrm{g}$ & $70.0 \mathrm{c}-\mathrm{g}$ & $47.5 \mathrm{~g}-\mathrm{j}$ & $72.5 \mathrm{a}-\mathrm{f}$ & 71.3 & $80.0 \mathrm{c}-\mathrm{h}$ \\
\hline CL0J095-4-6 & $61.31-n$ & $37.51-n$ & $70.0 \mathrm{a}-\mathrm{e}$ & $49.4 \mathrm{j}-\mathrm{n}$ & 70.5 & $100.0 \mathrm{a}-\mathrm{d}$ \\
\hline CL0J173-6-8 & $58.1 \mathrm{mn}$ & $35.0 \mathrm{mn}$ & $75.0 \mathrm{a}-\mathrm{c}$ & $46.3 \mathrm{k}-\mathrm{n}$ & 74.8 & $100.0 \mathrm{a}-\mathrm{d}$ \\
\hline HS6-3976 & $72.5 \mathrm{e}-\mathrm{k}$ & $55.0 \mathrm{f}-1$ & $65.0 \mathrm{a}-\mathrm{g}$ & $59.4 \mathrm{~d}-1$ & 64.4 & $100.0 \mathrm{a}-\mathrm{d}$ \\
\hline IA 3023 & $81.3 \mathrm{~b}-\mathrm{f}$ & $75.0 \mathrm{~b}-\mathrm{e}$ & $42.5 \mathrm{~h}-\mathrm{k}$ & $68.1 \mathrm{a}-\mathrm{h}$ & 62.1 & $89.5 \mathrm{a}-\mathrm{f}$ \\
\hline LD00-3309 & $69.4 \mathrm{~g}-1$ & $52.5 \mathrm{~g}-\mathrm{m}$ & $75.0 \mathrm{a}-\mathrm{c}$ & $67.5 \mathrm{a}-\mathrm{i}$ & 80.5 & $88.9 \mathrm{a}-\mathrm{f}$ \\
\hline LD01-5907 & $76.9 \mathrm{~d}-\mathrm{h}$ & $62.5 \mathrm{~d}-\mathrm{j}$ & $52.5 \mathrm{e}-\mathrm{h}$ & $61.3 \mathrm{a}-1$ & 60.9 & $100.0 \mathrm{a}-\mathrm{d}$ \\
\hline LD02-4485 & $79.4 \mathrm{c}-\mathrm{g}$ & $75.0 \mathrm{~b}-\mathrm{e}$ & $57.5 \mathrm{c}-\mathrm{h}$ & $62.5 \mathrm{a}-\mathrm{k}$ & 60.3 & $88.9 \mathrm{a}-\mathrm{f}$ \\
\hline LD02-9050 & $63.8 \mathrm{i}-\mathrm{n}$ & $47.5 \mathrm{i}-\mathrm{m}$ & 70.0 a-e & $45.61-n$ & 82.7 & $90.0 \mathrm{a}-\mathrm{f}$ \\
\hline LG00-3372 & $65.0 \mathrm{i}-\mathrm{n}$ & $40.0 \mathrm{k}-\mathrm{n}$ & $67.5 \mathrm{a}-\mathrm{f}$ & $56.3 \mathrm{f}-1$ & 50.1 & $111.1 \mathrm{ab}$ \\
\hline LG03-2979 & $63.8 \mathrm{i}-\mathrm{n}$ & $40.0 \mathrm{k}-\mathrm{n}$ & 70.0 a-e & $66.9 \mathrm{a}-\mathrm{i}$ & 70.3 & $89.5 \mathrm{a}-\mathrm{f}$ \\
\hline LG03-3191 & $67.5 \mathrm{~h}-\mathrm{n}$ & $47.5 \mathrm{i}-\mathrm{m}$ & $60.0 \mathrm{~b}-\mathrm{h}$ & $58.8 \mathrm{~d}-1$ & 53.8 & $111.7 \mathrm{ab}$ \\
\hline LG04-4717 & $66.9 \mathrm{~h}-\mathrm{n}$ & $50.0 \mathrm{~h}-\mathrm{m}$ & $52.5 \mathrm{e}-\mathrm{h}$ & $46.3 \mathrm{k}-\mathrm{n}$ & 66.8 & $90.0 \mathrm{a}-\mathrm{f}$ \\
\hline LG04-6000 & $81.3 \mathrm{~b}-\mathrm{f}$ & $72.5 \mathrm{~b}-\mathrm{f}$ & $47.5 \mathrm{~g}-\mathrm{j}$ & $66.9 \mathrm{a}-\mathrm{i}$ & 54.2 & $80.0 \mathrm{c}-\mathrm{h}$ \\
\hline LG05-4292 & $76.9 \mathrm{~d}-\mathrm{h}$ & $67.5 \mathrm{~d}-\mathrm{h}$ & $57.5 \mathrm{c}-\mathrm{h}$ & $65.6 \mathrm{a}-\mathrm{j}$ & 67.4 & $79.0 \mathrm{c}-\mathrm{h}$ \\
\hline LG05-4317 & $91 . .9 \mathrm{ab}$ & $87.5 \mathrm{a}-\mathrm{c}$ & 20.01 & $76.3 \mathrm{a}-\mathrm{c}$ & 60.0 & $52.7 \mathrm{~h}$ \\
\hline LG05-4464 & $63.1 \mathrm{j}-\mathrm{n}$ & $37.51-\mathrm{n}$ & $77.5 \mathrm{ab}$ & $33.1 \mathrm{n}$ & 69.4 & $100.0 \mathrm{a}-\mathrm{d}$ \\
\hline LG05-4832 & $64.4 \mathrm{i}-\mathrm{n}$ & $35.0 \mathrm{mn}$ & $72.5 \mathrm{a}-\mathrm{d}$ & $53.8 \mathrm{~g}-\mathrm{m}$ & 69.9 & $94.8 \mathrm{a}-\mathrm{e}$ \\
\hline LG90-2550 & $60.11-\mathrm{n}$ & $40.0 \mathrm{k}-\mathrm{n}$ & $77.5 \mathrm{ab}$ & $61.9 \mathrm{a}-1$ & 58.5 & $90.0 \mathrm{a}-\mathrm{f}$ \\
\hline LG92-1255 & $82.5 \mathrm{a}-\mathrm{e}$ & $75.0 \mathrm{~b}-\mathrm{e}$ & $42.5 \mathrm{~h}-\mathrm{k}$ & $63.8 \mathrm{a}-\mathrm{j}$ & 48.1 & $95.0 \mathrm{a}-\mathrm{e}$ \\
\hline LG94-1128 & $63.8 \mathrm{i}-\mathrm{n}$ & $35.0 \mathrm{mn}$ & $70.0 \mathrm{a}-\mathrm{e}$ & $60.6 \mathrm{~b}-1$ & 66.6 & $100.0 \mathrm{a}-\mathrm{d}$ \\
\hline LG94-1906 & $74.4 \mathrm{e}-\mathrm{i}$ & $57.5 \mathrm{e}-\mathrm{k}$ & $55.0 \mathrm{~d}-\mathrm{h}$ & $66.9 \mathrm{a}-\mathrm{i}$ & 58.0 & $84.2 \mathrm{~b}-\mathrm{g}$ \\
\hline LG97-7012 & $81.3 \mathrm{~b}-\mathrm{f}$ & $75.0 \mathrm{~b}-\mathrm{e}$ & $42.5 \mathrm{~h}-\mathrm{k}$ & $57.5 \mathrm{e}-1$ & 58.1 & $100.0 \mathrm{a}-\mathrm{d}$ \\
\hline LG98-1605 & $68.1 \mathrm{~h}-\mathrm{m}$ & $45.0 \mathrm{j}-\mathrm{n}$ & $72.5 \mathrm{a}-\mathrm{d}$ & $61.3 \mathrm{a}-1$ & 64.7 & $106.3 \mathrm{a}-\mathrm{c}$ \\
\hline Magellan & $74.4 \mathrm{e}-\mathrm{i}$ & $57.5 \mathrm{e}-\mathrm{k}$ & $57.5 \mathrm{c}-\mathrm{h}$ & $60.0 \mathrm{c}-1$ & 74.2 & $89.5 \mathrm{a}-\mathrm{f}$ \\
\hline Maverick & $69.4 \mathrm{~g}-1$ & $45.0 \mathrm{j}-\mathrm{n}$ & $60.0 \mathrm{~b}-\mathrm{h}$ & $51.3 \mathrm{i}-\mathrm{m}$ & 87.2 & $95.0 \mathrm{a}-\mathrm{e}$ \\
\hline NE3001 & $61.9 \mathrm{k}-\mathrm{n}$ & $35.0 \mathrm{mn}$ & $80.0 \mathrm{a}$ & $63.1 \mathrm{a}-\mathrm{j}$ & 66.2 & $84.2 \mathrm{~b}-\mathrm{g}$ \\
\hline PI 398.881 & $76.3 \mathrm{e}-\mathrm{h}$ & $65.0 \mathrm{~d}-\mathrm{i}$ & $50.0 \mathrm{f}-\mathrm{i}$ & $58.1 \mathrm{e}-1$ & 69.2 & $85.0 \mathrm{a}-\mathrm{g}$ \\
\hline PI 404.188A & $69.4 \mathrm{~g}-1$ & $50.0 \mathrm{~h}-\mathrm{m}$ & $70.0 \mathrm{a}-\mathrm{e}$ & $75.0 \mathrm{a}-\mathrm{d}$ & 54.8 & $61.1 \mathrm{gh}$ \\
\hline PI 427.136 & $68.1 \mathrm{~h}-\mathrm{m}$ & $47.5 \mathrm{~h}-\mathrm{m}$ & $65.0 \mathrm{a}-\mathrm{g}$ & $73.8 \mathrm{a}-\mathrm{e}$ & 87.7 & $72.2 \mathrm{e}-\mathrm{h}$ \\
\hline PI 437.169B & $89.4 \mathrm{a}-\mathrm{c}$ & $90.0 \mathrm{ab}$ & $32.5 \mathrm{i}-1$ & $66.3 \mathrm{a}-\mathrm{i}$ & 57.1 & $88.2 \mathrm{a}-\mathrm{g}$ \\
\hline PI 507.681B & $65.0 \mathrm{i}-\mathrm{n}$ & $47.5 \mathrm{i}-\mathrm{m}$ & $67.5 \mathrm{a}-\mathrm{f}$ & $37.5 \mathrm{mn}$ & 69.0 & $100.0 \mathrm{ab}$ \\
\hline PI 518.751 & $79.4 \mathrm{c}-\mathrm{g}$ & $75.0 \mathrm{~b}-\mathrm{e}$ & $52.5 \mathrm{e}-\mathrm{h}$ & $68.1 \mathrm{a}-\mathrm{h}$ & 65.1 & $94.5 \mathrm{a}-\mathrm{e}$ \\
\hline PI 561.370 & $79.4 \mathrm{c}-\mathrm{g}$ & $72.5 \mathrm{~b}-\mathrm{f}$ & $47.5 \mathrm{~g}-\mathrm{j}$ & $77.5 \mathrm{a}$ & 59.2 & $66.7 \mathrm{f}-\mathrm{h}$ \\
\hline PI 574.486 & $93.1 \mathrm{a}$ & $97.5 \mathrm{a}$ & $25.0 \mathrm{kl}$ & $60.0 c-1$ & 65.6 & $105.6 \mathrm{a}-\mathrm{c}$ \\
\hline Prohio & $70.6 \mathrm{f}-1$ & $50.0 \mathrm{~h}-\mathrm{m}$ & $65.0 \mathrm{a}-\mathrm{g}$ & $53.8 \mathrm{~g}-\mathrm{m}$ & 79.3 & $90.0 \mathrm{a}-\mathrm{f}$ \\
\hline S06-13640 & $87.5 \mathrm{a}-\mathrm{d}$ & $80.0 \mathrm{a}-\mathrm{d}$ & $30.0 \mathrm{j}-1$ & $52.5 \mathrm{~h}-\mathrm{m}$ & 71.7 & $112.5 \mathrm{a}$ \\
\hline Skylla & $77.5 \mathrm{~d}-\mathrm{h}$ & $67.5 \mathrm{~d}-\mathrm{h}$ & $45.0 \mathrm{~h}-\mathrm{j}$ & $59.4 \mathrm{~d}-1$ & 73.0 & $94.5 \mathrm{a}-\mathrm{e}$ \\
\hline TN05-3027 & $60.01-\mathrm{n}$ & $27.5 \mathrm{n}$ & $82.5 \mathrm{a}$ & $61.9 \mathrm{a}-1$ & 60.2 & $112.5 \mathrm{a}$ \\
\hline U03-100612 & $73.8 \mathrm{e}-\mathrm{j}$ & $62.5 \mathrm{~d}-\mathrm{j}$ & $52.5 \mathrm{e}-\mathrm{h}$ & $54.4 \mathrm{~g}-1$ & 84.5 & $94.8 \mathrm{a}-\mathrm{e}$ \\
\hline Archer & $56.9 \mathrm{n}$ & $42.5 \mathrm{k}-\mathrm{n}$ & $80.0 \mathrm{a}$ & $69.4 \mathrm{a}-\mathrm{g}$ & 63.1 & $76.5 \mathrm{~d}-\mathrm{h}$ \\
\hline Sloan & $90.0 \mathrm{a}-\mathrm{c}$ & $90.0 \mathrm{ab}$ & $30.0 \mathrm{j}-1$ & $76.9 \mathrm{ab}$ & 55.5 & $92.3 \mathrm{a}-\mathrm{f}$ \\
\hline$P$ & $<0.0001$ & $<0.0001$ & $<0.0001$ & $<0.0001$ & 0.1504 & 0.0120 \\
\hline
\end{tabular}

${ }^{\mathrm{z}}$ Lowercase letters indicate significant differences between parents within a column. 
ranged from 57.8 to $106 \%, 16.1$ to $94.8 \%, 52.7$ to $112.5 \%$, and 50 to $111.1 \%$ for $P$. lutarium (Table 1), P. oopapillum (Table 2 ), $P$. sylvaticum (Table 3), and P. torulosum (Table 4), respectively. Five parents, 'LG03-3191,' 'LG04-4717,' 'LG05-4464,' 'LG05-4832,' and 'Maverick,' had significantly less root rot severity than 'Sloan' to all four Pythium spp. evaluated in the root rot assay. Nineteen of the parents had significantly less root rot than 'Sloan' to three Pythium spp. Of the remaining parents, 12 were resistant to root rot caused by two species and 5 were resistant to root rot caused by one species. The hub parent to the SoyNAM populations, 'IA 3023,' had root rot similar to 'Sloan' caused by $P$. lutarium, $P$. oopapillum, and $P$. sylvaticum but had significantly less root rot caused by P. torulosum.

Correlation of seed and root rot assessments. Seed rot and root rot assessments were compared for each Pythium species tested. A significant correlation was found between seed rot severity, rotted seeds, and germination for all species tested $(P<0.0001$; Table 5). The correlation coefficient ranged from 0.7069 to 0.9723 ,
-0.6444 to -0.9497 , and -0.8764 to -0.9801 for seed rot severity and rotted seeds, seed rot severity and germination, and rotted seeds and germination, respectively. A significant correlation was also found between root rot severity and adjusted emergence for all species tested $(P<0.0001$; Table 6$)$, and the correlation coefficient ranged from -0.5858 to -0.8693 . No significant correlation $(P>0.05)$ was identified between root rot severity and dry root weight. For $P$. oopapillum, a significant relationship between adjusted dry root weight and adjusted emergence was identified in the root rot assay $(P=0.0197)$ but not for the other three species tested.

Correlation of seed and root rot severity. Seed rot severity was compared between the four Pythium spp (Table 7). A weak but significant linear relationship was detected between seed rot caused by $P$. sylvaticum and $P$. torulosum $(P=0.0025)$. Only $20.2 \%$ of the variation observed in seed rot severity caused by $P$. sylvaticum was explained by the seed rot severity caused by $P$. torulosum. There was no relationship between $P$. lutarium or

Table 4. Resistance assessments of the 40 SoyNAM parents to Pythium torulosum in seed and root rot assays ${ }^{\mathrm{z}}$

\begin{tabular}{|c|c|c|c|c|c|c|}
\hline \multirow[b]{2}{*}{ NAM parent } & \multicolumn{3}{|c|}{ Seed rot assay } & \multicolumn{3}{|c|}{ Root rot assay } \\
\hline & $\begin{array}{l}\text { Seed rot severity } \\
(\%)\end{array}$ & $\begin{array}{c}\text { Rotted seeds } \\
(\%)\end{array}$ & $\begin{array}{c}\text { Germination } \\
(\%)\end{array}$ & $\begin{array}{c}\text { Root rot severity } \\
(\%)\end{array}$ & $\begin{array}{c}\text { Adjusted dry root weight } \\
(\%)\end{array}$ & $\begin{array}{c}\text { Adjusted emergence } \\
(\%)\end{array}$ \\
\hline $4 \mathrm{~J} 105-3-4$ & $30.01-0$ & $2.5 \mathrm{fg}$ & $97.5 \mathrm{ab}$ & $26.3 n-p$ & 71.6 & $111.1 \mathrm{a}$ \\
\hline $5 \mathrm{M} 20-2-5-2$ & $33.1 \mathrm{i}-\mathrm{m}$ & $5.0 \mathrm{e}-\mathrm{g}$ & $95.0 \mathrm{a}-\mathrm{c}$ & $40.6 \mathrm{~h}-1$ & 69.6 & $94.1 \mathrm{a}-\mathrm{d}$ \\
\hline CL0J095-4-6 & $33.1 \mathrm{i}-\mathrm{m}$ & $10.0 \mathrm{~d}-\mathrm{f}$ & $90.0 \mathrm{a}-\mathrm{e}$ & $33.11-\mathrm{n}$ & 82.1 & $89.5 \mathrm{a}-\mathrm{e}$ \\
\hline CL0J173-6-8 & $22.5 \mathrm{p}$ & $0.0 \mathrm{~g}$ & $100.0 \mathrm{a}$ & $25.0 \mathrm{n}-\mathrm{p}$ & 62.4 & $105.3 \mathrm{ab}$ \\
\hline HS6-3976 & $34.7 \mathrm{~g}-\mathrm{m}$ & $7.5 \mathrm{~d}-\mathrm{g}$ & $90.0 \mathrm{a}-\mathrm{e}$ & $40.6 \mathrm{~h}-1$ & 66.6 & $95.0 \mathrm{a}-\mathrm{d}$ \\
\hline IA3023 & $34.4 \mathrm{~h}-\mathrm{m}$ & $10.0 \mathrm{~d}-\mathrm{f}$ & $92.5 \mathrm{a}-\mathrm{d}$ & 21.9 op & 65.8 & $100.0 \mathrm{a}-\mathrm{c}$ \\
\hline LD00-3309 & $36.7 \mathrm{f}-\mathrm{k}$ & $10.0 \mathrm{~d}-\mathrm{f}$ & $85.0 \mathrm{c}-\mathrm{f}$ & $36.3 \mathrm{k}-\mathrm{m}$ & 74.1 & $100.0 \mathrm{a}-\mathrm{c}$ \\
\hline LD01-5907 & $40.6 \mathrm{~d}-\mathrm{h}$ & $20.0 \mathrm{a}-\mathrm{c}$ & $82.5 \mathrm{~d}-\mathrm{f}$ & $47.5 \mathrm{~d}-\mathrm{i}$ & 63.6 & $76.5 \mathrm{~b}-\mathrm{f}$ \\
\hline LD02-4485 & $37.2 \mathrm{f}-\mathrm{k}$ & $12.5 \mathrm{c}-\mathrm{e}$ & $85.0 \mathrm{c}-\mathrm{f}$ & $46.3 \mathrm{~d}-\mathrm{j}$ & 59.1 & $106.3 \mathrm{ab}$ \\
\hline LD02-9050 & $35.0 \mathrm{~g}-\mathrm{m}$ & $0.0 \mathrm{~g}$ & $100.0 \mathrm{a}$ & $54.4 \mathrm{~cd}$ & 68.0 & $77.8 \mathrm{a}-\mathrm{f}$ \\
\hline LG00-3372 & $30.01-0$ & $5.0 \mathrm{e}-\mathrm{g}$ & $95.0 \mathrm{a}-\mathrm{c}$ & $37.5 \mathrm{j}-\mathrm{m}$ & 50.2 & $100.0 \mathrm{a}-\mathrm{c}$ \\
\hline LG03-2979 & $36.4 \mathrm{f}-1$ & $7.5 \mathrm{~d}-\mathrm{g}$ & $85.0 \mathrm{c}-\mathrm{f}$ & $44.4 \mathrm{e}-\mathrm{k}$ & 78.9 & $80.0 \mathrm{a}-\mathrm{f}$ \\
\hline LG03-3191 & $26.1 \mathrm{n}-\mathrm{p}$ & $0.0 \mathrm{~g}$ & $97.5 \mathrm{ab}$ & $51.3 \mathrm{~d}-\mathrm{f}$ & 49.2 & $70.0 \mathrm{c}-\mathrm{f}$ \\
\hline LG04-4717 & $38.6 \mathrm{~d}-\mathrm{i}$ & $5.0 \mathrm{e}-\mathrm{g}$ & $92.5 \mathrm{a}-\mathrm{d}$ & $33.81-\mathrm{n}$ & 64.7 & $85.0 \mathrm{a}-\mathrm{e}$ \\
\hline LG04-6000 & $40.8 \mathrm{c}-\mathrm{h}$ & $15.0 \mathrm{~b}-\mathrm{d}$ & $82.5 \mathrm{~d}-\mathrm{f}$ & $30.0 \mathrm{~m}-\mathrm{o}$ & 68.1 & $85.0 \mathrm{a}-\mathrm{e}$ \\
\hline LG05-4292 & $36.1 \mathrm{f}-1$ & $2.5 \mathrm{fg}$ & $87.5 \mathrm{~b}-\mathrm{f}$ & $39.4 \mathrm{i}-\mathrm{m}$ & 49.6 & $100.0 \mathrm{a}-\mathrm{c}$ \\
\hline LG05-4317 & $31.9 \mathrm{j}-\mathrm{n}$ & $2.5 \mathrm{fg}$ & $97.5 \mathrm{ab}$ & $46.9 \mathrm{~d}-\mathrm{j}$ & 94.3 & $72.2 \mathrm{~b}-\mathrm{f}$ \\
\hline LG05-4464 & $36.3 \mathrm{f}-1$ & $2.5 \mathrm{fg}$ & $97.5 \mathrm{ab}$ & 21.3 op & 63.8 & $100.0 \mathrm{a}-\mathrm{c}$ \\
\hline LG05-4832 & $34.4 \mathrm{~h}-\mathrm{m}$ & $2.5 \mathrm{fg}$ & $97.5 \mathrm{ab}$ & $40.0 \mathrm{i}-1$ & 77.7 & $88.9 \mathrm{a}-\mathrm{e}$ \\
\hline LG90-2550 & $37.8 \mathrm{e}-\mathrm{j}$ & $7.5 \mathrm{~d}-\mathrm{g}$ & $90.0 \mathrm{a}-\mathrm{e}$ & $39.4 \mathrm{i}-\mathrm{m}$ & 69.2 & $95.0 \mathrm{a}-\mathrm{d}$ \\
\hline LG92-1255 & $28.8 \mathrm{~m}-\mathrm{p}$ & $2.5 \mathrm{fg}$ & $100.0 \mathrm{a}$ & $41.3 \mathrm{~g}-1$ & 60.2 & $90.0 \mathrm{a}-\mathrm{d}$ \\
\hline LG94-1128 & $26.3 \mathrm{n}-\mathrm{p}$ & $0.0 \mathrm{~g}$ & $100.0 \mathrm{a}$ & $45.6 \mathrm{~d}-\mathrm{k}$ & 76.6 & $75.0 \mathrm{~b}-\mathrm{f}$ \\
\hline LG94-1906 & $34.4 \mathrm{~h}-\mathrm{m}$ & $5.0 \mathrm{e}-\mathrm{g}$ & $92.5 \mathrm{a}-\mathrm{d}$ & $70.0 \mathrm{~b}$ & 71.6 & $50.0 \mathrm{fg}$ \\
\hline LG97-7012 & $33.8 \mathrm{i}-\mathrm{m}$ & $5.0 \mathrm{e}-\mathrm{g}$ & $95.0 \mathrm{a}-\mathrm{c}$ & $63.1 \mathrm{bc}$ & 57.9 & $61.1 \mathrm{~d}-\mathrm{f}$ \\
\hline LG98-1605 & $41.9 \mathrm{c}-\mathrm{f}$ & $10.0 \mathrm{~d}-\mathrm{f}$ & 90.0 a-e & $41.9 \mathrm{f}-1$ & 51.5 & $85.0 \mathrm{a}-\mathrm{e}$ \\
\hline Magellan & $33.8 \mathrm{i}-\mathrm{m}$ & $10.0 \mathrm{~d}-\mathrm{f}$ & $90.0 \mathrm{a}-\mathrm{e}$ & $23.1 \mathrm{op}$ & 90.8 & $95.0 \mathrm{a}-\mathrm{d}$ \\
\hline Maverick & $36.3 \mathrm{f}-1$ & $5.0 \mathrm{e}-\mathrm{g}$ & $95.0 \mathrm{a}-\mathrm{c}$ & $33.11-n$ & 55.9 & $94.7 \mathrm{a}-\mathrm{d}$ \\
\hline NE3001 & $38.0 \mathrm{e}-\mathrm{j}$ & $7.5 \mathrm{~d}-\mathrm{g}$ & $85.0 \mathrm{c}-\mathrm{f}$ & $33.11-\mathrm{n}$ & 61.3 & $100.0 \mathrm{a}-\mathrm{c}$ \\
\hline PI 398.881 & $41.9 \mathrm{c}-\mathrm{f}$ & $12.5 \mathrm{c}-\mathrm{e}$ & $92.5 \mathrm{a}-\mathrm{d}$ & $36.3 \mathrm{k}-\mathrm{m}$ & 69.3 & $82.4 \mathrm{a}-\mathrm{f}$ \\
\hline PI 404.188A & $35.2 \mathrm{~g}-\mathrm{m}$ & $12.5 \mathrm{c}-\mathrm{e}$ & 80.0 ef & $53.1 \mathrm{de}$ & 99.2 & $82.4 \mathrm{a}-\mathrm{f}$ \\
\hline PI 427.136 & $39.1 \mathrm{~d}-\mathrm{i}$ & $12.5 \mathrm{c}-\mathrm{e}$ & $85.0 \mathrm{c}-\mathrm{f}$ & $50.0 \mathrm{~d}-\mathrm{h}$ & 73.5 & $72.2 \mathrm{~b}-\mathrm{f}$ \\
\hline PI 437.169B & $45.0 \mathrm{~b}-\mathrm{d}$ & $15.0 \mathrm{~b}-\mathrm{d}$ & $87.5 \mathrm{~b}-\mathrm{e}$ & $54.4 \mathrm{~cd}$ & 89.7 & $81.3 \mathrm{a}-\mathrm{f}$ \\
\hline PI 507.681B & $43.9 \mathrm{~b}-\mathrm{e}$ & $15.0 \mathrm{~b}-\mathrm{d}$ & $82.5 \mathrm{~d}-\mathrm{f}$ & $50.6 \mathrm{~d}-\mathrm{g}$ & 64.1 & $68.4 c-f$ \\
\hline PI 518.751 & $36.6 \mathrm{f}-1$ & $7.5 \mathrm{~d}-\mathrm{g}$ & $87.5 \mathrm{~b}-\mathrm{e}$ & $17.5 \mathrm{p}$ & 61.6 & $100.0 \mathrm{a}-\mathrm{c}$ \\
\hline PI 561.370 & $50.5 \mathrm{ab}$ & $20.0 \mathrm{a}-\mathrm{c}$ & $82.5 \mathrm{~d}-\mathrm{f}$ & $53.1 \mathrm{de}$ & 59.7 & $72.2 \mathrm{~b}-\mathrm{f}$ \\
\hline PI 574.486 & $55.6 \mathrm{a}$ & $25.0 \mathrm{a}$ & $75.0 \mathrm{f}$ & $45.6 \mathrm{~d}-\mathrm{k}$ & 71.8 & 88.9 a-e \\
\hline Prohio & $30.6 \mathrm{k}-\mathrm{o}$ & $0.0 \mathrm{~g}$ & $100.0 \mathrm{a}$ & 22.5 op & 80.3 & $95.0 \mathrm{a}-\mathrm{d}$ \\
\hline S06-13640 & $40.6 \mathrm{~d}-\mathrm{h}$ & $15.0 \mathrm{~b}-\mathrm{d}$ & 90.0 a-e & $63.8 \mathrm{bc}$ & 48.7 & $55.6 \mathrm{e}-\mathrm{g}$ \\
\hline Skylla & $47.3 \mathrm{~b}-\mathrm{c}$ & $22.5 \mathrm{ab}$ & $75.0 \mathrm{f}$ & $53.1 \mathrm{de}$ & 82.0 & $63.2 \mathrm{~d}-\mathrm{f}$ \\
\hline TN05-3027 & 24.2 op & $2.5 \mathrm{fg}$ & $95.0 \mathrm{a}-\mathrm{c}$ & $41.9 \mathrm{f}-1$ & 70.8 & $88.2 \mathrm{a}-\mathrm{e}$ \\
\hline U03-100612 & $33.9 \mathrm{i}-\mathrm{m}$ & $7.5 \mathrm{~d}-\mathrm{g}$ & $90.0 \mathrm{a}-\mathrm{e}$ & $33.11-\mathrm{n}$ & 63.7 & $94.7 \mathrm{a}-\mathrm{d}$ \\
\hline Archer & $41.3 \mathrm{c}-\mathrm{g}$ & $12.5 \mathrm{c}-\mathrm{e}$ & $90.0 \mathrm{a}-\mathrm{e}$ & $39.4 \mathrm{i}-\mathrm{m}$ & 71.8 & $84.2 \mathrm{a}-\mathrm{f}$ \\
\hline Sloan & $45.0 \mathrm{~b}-\mathrm{d}$ & $12.5 \mathrm{c}-\mathrm{e}$ & $90.0 \mathrm{a}-\mathrm{e}$ & 86.9 a & 58.4 & $23.5 \mathrm{~g}$ \\
\hline$P$ & $<0.0001$ & $<0.0001$ & $<0.0001$ & $<0.0001$ & 0.8532 & 0.0033 \\
\hline
\end{tabular}

${ }_{\mathrm{z}}$ Lowercase letters indicate significant differences between parents within a column. 
$P$. oopapillum and seed rot caused by the other three Pythium spp. tested $(P>0.05)$. When root rot severity was compared between the four Pythium spp. (Table 8), a significant relationship between $P$. lutarium and $P$. sylvaticum, $P$. lutarium and $P$. torulosum, and $P$. oopapillum and $P$. torulosum was detected $(P=0.0016$, 0.0311 , and 0.0212 , respectively). No relationship was identified between $P$. lutarium and $P$. oopapillum, $P$. oopapillum and $P$. sylvaticum, or $P$. sylvaticum and $P$. torulosum $(P>0.05)$. Moreover, when seed and root rot severities were compared within each Pythium species (Table 9), a relationship between the two variables was detected for $P$. sylvaticum and $P$. torulosum $(P=$ 0.0056 and 0.0344 , respectively). Seed rot severity explained 17.2 and $10.5 \%$ of the variation seen in root rot for P. sylvaticum and $P$. torulosum, respectively.

Resistance to Pythium spp. To be considered resistant to a Pythium species a parent had to be significantly different from the susceptible check 'Sloan' in both the seed and root rot assays. Overall, only one of the SoyNAM parents, 'Maverick,' consistently had significantly lower seed and root rot severity and thus was considered resistant. Thirteen parents were resistant to three of the species tested, and 12 parents were resistant to two of the species tested. Of the remaining 12 parents, 5 were resistant to seed and root rot caused by only $P$. lutarium, 1 to $P$. sylvaticum, and 6 to $P$. torulosum. Three parents, 'LG98-1605,' 'PI 574.486,' and 'S06-13640,' were susceptible to all of the species tested. Only four parents, 'LD02-4485,' 'LG04-4717,' 'LG90-2550,' and 'Maverick,' were resistant to seedling disease caused by $P$. oopapillum, in comparison with 'Sloan.'

\section{Discussion}

The SoyNAM parents represent a diverse set of U.S.-adapted cultivars and plant introductions, but their resistance to many diseases is unknown. In this study, the SoyNAM parents were screened for resistance to four of the most prevalent Pythium spp. that occur in Iowa (Matthiesen et al. 2016) and across the Midwest (Rojas et al. 2017b). A continuous range of phenotypic variation was observed in both seed and root rot severity caused by each Pythium species on this collection of germplasm and thus indicated that the SoyNAM parents differed in their susceptibility to seed rot and root rot caused by each species. These data are consistent with resistance to other necrotrophic pathogens, such as Fusarium spp. and Rhizoctonia solani, which are also known to cause seed and seedling disease in soybean.

One of the parents, 'Maverick,' was resistant to both seed and root rot caused by $P$. lutarium, $P$. oopapillum, $P$. sylvaticum, and
$P$. torulosum. An additional 13 parents were resistant to three of the species tested for both seed and root rot severity. Identifying germplasm with disease resistance to multiple Pythium spp. would be extremely useful for soybean breeders considering that multiple Pythium spp. have been recovered from soybean seedlings with seedling disease symptoms (Rojas et al. 2017a). Furthermore, $P$. lutarium, $P$. oopapillum, $P$. sylvaticum, and $P$. torulosum were among the top 10 most prevalent species recovered from diseased soybean seedlings in the Midwest in 2011 and 2012 (Rojas et al. 2017a).

The susceptible check in our assays, 'Sloan,' appeared to have some level of resistance to the P. oopapillum isolate. Only four parents, 'LD02-4485,' 'LG04-4717,' 'LG90-2550,' and 'Maverick,' were resistant to $P$. oopapillum in both seed and root rot when compared with 'Sloan.' Ten of the parents had significantly more seed rot and five parents had significantly more root rot compared with the susceptible check. In future research, it may be of benefit to use 'LG05-4317' as a susceptible check for evaluations of $P$. oopapillum because it had more severe seed and root rot.

Because 'IA3023' is the hub parent of the SoyNAM populations, it would be useful to compare the other parents with 'IA3023.' 'IA3023' had an equivalent or higher level of seed and root rot severity to $P$. oopapillum and $P$. sylvaticum when compared with 'Sloan' but only had similar root rot severity to $P$. lutarium. Under those conditions, it would therefore be the susceptible parent in the SoyNAM populations. However, it had less severe disease when inoculated with $P$. torulosum.

Our data revealed that the assay used to screen for resistance can affect the results. Resistance probably depends on the timing of infection during the development of the seedling. In the seed rot severity assay, seeds were directly infected by the pathogen, whereas in the root rot severity assay, infection of the germinated seedling is delayed because of the soil layer acting as a barrier between the inoculum and the seed. Consequently, the seed germinated before infection took place. Additionally, these assays correspond to the two phases of infection that are observed in seedling diseases: preemergence damping off and postemergence damping off and root rot. Therefore, the seed rot severity assay measures seed rot, germination, and rotted seeds, which are variables that can be associated with pre-emergence damping off. The root rot severity assay measures variables associated with postemergence damping off and root rot, including root rot severity, adjusted emergence, and adjusted dry root weight. Other studies have identified soybean resistance to Pythium spp. in root rot and hypocotyl assays and did not consider

Table 5. Correlation coefficient and $P$ of pairwise correlation analysis between seed rot assessments: seed rot severity (SRS), rotted seeds (ROT), and germination (GER) caused by Pythium sylvaticum, P. lutarium, P. oopapillum, and P. torulosum

\begin{tabular}{|c|c|c|c|c|c|c|c|c|c|c|c|c|}
\hline \multirow[b]{2}{*}{ Assessment } & \multicolumn{3}{|c|}{ P. lutarium } & \multicolumn{3}{|c|}{ P. oopapillum } & \multicolumn{3}{|c|}{ P. sylvaticum } & \multicolumn{3}{|c|}{ P.torulosum } \\
\hline & SRS & ROT & $\overline{\text { GER }}$ & SRS & ROT & $\overline{\text { GER }}$ & SRS & ROT & GER & SRS & ROT & GER \\
\hline$\overline{\text { SRS }}$ & 1 & & & 1 & & & 1 & & & 1 & & \\
\hline ROT & 0.7069 & 1 & & 0.8899 & 1 & & 0.9723 & 1 & & 0.8555 & 1 & \\
\hline & $<0.0001$ & & & $<0.0001$ & & & $<0.0001$ & & & $<0.0001$ & & \\
\hline GER & $\begin{array}{l}-0.6444 \\
<0.0001\end{array}$ & $\begin{array}{l}-0.9801 \\
<0.0001\end{array}$ & 1 & $\begin{array}{l}-0.7823 \\
<0.0001\end{array}$ & $\begin{array}{l}-0.9067 \\
<0.0001\end{array}$ & 1 & $\begin{array}{l}-0.9497 \\
<0.0001\end{array}$ & $\begin{array}{l}-0.9315 \\
<0.0001\end{array}$ & 1 & $\begin{array}{l}-0.7555 \\
<0.0001\end{array}$ & $\begin{array}{l}-0.8764 \\
<0.0001\end{array}$ & 1 \\
\hline
\end{tabular}

Table 6. Correlation coefficient and $P$ of pairwise correlation analysis between root rot assessments: root rot severity (RRS), adjusted dry root weight (DRW), and emergence (EME) caused by Pythium sylvaticum, P. lutarium, P. oopapillum, and P. torulosum

\begin{tabular}{|c|c|c|c|c|c|c|c|c|c|c|c|c|}
\hline \multirow[b]{2}{*}{ Assessment } & \multicolumn{3}{|c|}{ P. lutarium } & \multicolumn{3}{|c|}{ P. oopapillum } & \multicolumn{3}{|c|}{ P. sylvaticum } & \multicolumn{3}{|c|}{ P. torulosum } \\
\hline & RRS & DRW & $\overline{\text { EME }}$ & RRS & DRW & $\overline{\text { EME }}$ & RRS & DRW & $\overline{\text { EME }}$ & RRS & DRW & $\overline{\text { EME }}$ \\
\hline$\overline{R R S}$ & 1 & & & 1 & & & 1 & & & 1 & & \\
\hline DRW & $\begin{array}{c}-0.2042 \\
0.1891\end{array}$ & 1 & & $\begin{array}{l}0.2121 \\
0.1721\end{array}$ & 1 & & $\begin{array}{c}-0.3414 \\
0.0250\end{array}$ & 1 & & $\begin{array}{c}-0.0700 \\
0.6556\end{array}$ & 1 & \\
\hline EME & $\begin{array}{l}-0.7099 \\
<0.0001\end{array}$ & $\begin{array}{l}0.2986 \\
0.0517\end{array}$ & 1 & $\begin{array}{l}-0.8506 \\
<0.0001\end{array}$ & $\begin{array}{c}-0.3546 \\
0.0197\end{array}$ & 1 & $\begin{array}{l}-0.5858 \\
<0.0001\end{array}$ & $\begin{array}{c}-0.0022 \\
0.9887\end{array}$ & 1 & $\begin{array}{l}-0.8693 \\
<0.0001\end{array}$ & $\begin{array}{l}0.0100 \\
0.9494\end{array}$ & 1 \\
\hline
\end{tabular}


seed rot (Bates et al. 2008; Ellis et al. 2013; Kirkpatrick et al. 2006; Rod et al. 2018; Rosso et al. 2008).

We observed that some of the SoyNAM parents were more susceptible to seed rot than to root rot. This observed difference in the level of resistance based on assay could be caused by changes in exudation during development from the seed to the seedling. Graham (1991) showed that the concentrations of isoflavonoids and flavonoids are affected by the age of the developing seedling. Alternatively, the level of resistance may reflect the composition of seed exudates produced by a soybean line. Avanzato and Rupe (2011) demonstrated that the susceptibility of soybean cultivars to infection by $P$. aphanidermatum was affected by the composition of seed exudates. The exudates of the resistant cultivar, 'Archer,' had a lower concentration of carbohydrates, lipids, and proteins but a higher isoflavone concentration compared with 'Hutcheson,' which is more susceptible to P. aphanidermatum (Avanzato and Rupe 2011).

Seed rot severity caused by $P$. sylvaticum had a weak correlation with root rot caused by $P$. sylvaticum. The same is true for $P$. torulosum. Only weak and insignificant correlations were detected between seed and root rot severity caused by the same species,

Table 7. Correlation coefficient and $P$ of pairwise correlation analysis between seed rot severity caused by Pythium sylvaticum, P. lutarium, P. oopapillum, and $P$. torulosum

\begin{tabular}{lcccc}
\hline & P. lutarium & P. oopapillum & P. sylvaticum & P. torulosum \\
\hline P. lutarium & 1 & & & \\
P. oopapillum & $0.2366^{\mathrm{y}}$ & 1 & & \\
& $0.1266^{\mathrm{z}}$ & & & \\
P. sylvaticum & 0.2611 & 0.2784 & 1 & \\
& 0.0908 & 0.0706 & & \\
P. torulosum & 0.0941 & 0.1406 & 0.4497 & 1 \\
& 0.5482 & 0.3684 & 0.0025 & \\
\hline
\end{tabular}

${ }^{y}$ Correlation coefficient.

${ }^{\mathrm{z}} P$ value.

Table 8. Correlation coefficient and $P$ of pairwise correlation analysis between root rot severity caused by Pythium sylvaticum, P. lutarium, P. oopapillum, and $P$. torulosum

\begin{tabular}{lcccc}
\hline & P. lutarium & P. oopapillum & P. sylvaticum & P. torulosum \\
\hline P. lutarium & 1 & & & \\
P. oopapillum & $0.1948^{\mathrm{y}}$ & 1 & & \\
& $0.2106^{\mathrm{z}}$ & & & \\
P. sylvaticum & 0.4662 & 0.1569 & 1 & \\
& 0.0016 & 0.3152 & & \\
P. torulosum & 0.3293 & 0.3504 & 0.2882 & 1 \\
& 0.0311 & 0.0212 & 0.0609 & \\
\hline
\end{tabular}

y Correlation coefficient.

${ }^{\mathrm{z}} P$ value.

Table 9. Correlation coefficient and $P$ of pairwise correlation analysis between Pythium sylvaticum, $P$. lutarium, P. oopapillum, and $P$. torulosum seed and root rot severities

\begin{tabular}{lc}
\hline Species & Correlation coefficient and $\boldsymbol{P}$ value \\
\hline P. lutarium & $0.1550^{\mathrm{y}}$ \\
& $0.3210^{\mathrm{z}}$ \\
P. oopapillum & 0.2156 \\
& 0.1650 \\
P. sylvaticum & 0.4153 \\
& 0.0056 \\
P. torulosum & 0.3234 \\
& 0.0344 \\
\hline
\end{tabular}

\footnotetext{
${ }^{\mathrm{y}}$ Correlation coefficient.
}

${ }^{\mathrm{z}} P$ value. suggesting that different loci could contribute to resistance to seed and root rot. In addition, correlations between seed and root rot caused by different species were also weak. There was a weak to insignificant relationship between seed rot caused by the four species, as well as for root rot. These data suggest different loci could contribute to resistance to different Pythium spp. Similarly, Rod et al. (2018) showed that four cultivars, resistant to $P$. ultimum var. ultimum, were only partially resistant to $P$. irregulare and $P$. sylvaticum. However, in this study only four of the 102 ancestral lines, originally screened for resistance to $P$. ultimum var. ultimum, were screened for resistance to the other two species. Thus, it is unknown whether there was a strong correlation between resistance of those Pythium spp.

In our study, parents were screened with one isolate of each Pythium species, representative of isolates that were collected in Iowa. Matthiesen et al. (2016) found no difference in aggressiveness of isolates of the same species within Iowa. Thus, each species used in our study was chosen to be representative of that species in Iowa. It is typical when screening for resistance to use a representative isolate of a species. For example, Rod et al. (2018) screened ancestral cultivars for resistance to $P$. ultimum var. ultimum with only one isolate. Similarly, Rosso et al. (2008) used a single isolate of $P$. aphanidermatum to evaluate an 'Archer' $\times$ 'Hutcheson' population to identify QTLs for resistance. It would be beneficial to verify these reactions with isolates relevant to the region in which resistance would be deployed before use in a breeding program.

Aggressiveness varied between Pythium spp. in this study. In the seed rot assay, $P$. sylvaticum caused the most severe seed rot, the highest percentage of rotted seeds, and the lowest germination on average, at $72.5,57.1$, and $58.2 \%$, respectively. Both $P$. lutarium and $P$. torulosum had a much lower seed rot severity, between 36 and $37 \%$. In the root rot severity assay, $P$. oopapillum caused the most disease on average, with a root rot severity of $70 \%$ and adjusted emergence of $63.7 \%$. P. torulosum caused the least amount of root rot at $42 \%$ severity. Similar observations about aggressiveness among Pythium spp. have been observed by Matthiesen et al. (2016) and Rojas et al. (2017a).

We used laboratory and growth chamber assays to screen soybean germplasm for resistance to four Pythium spp. We presume that the parents showing resistance in these assays would also be resistant in the field. Resistance of pea to P. ultimum identified in laboratory and greenhouse assays was also identified in field tests (Ohh et al. 1978). However, Zhang et al. (2013) noted that resistance of soybean to Fusarium spp. in greenhouse assays was significantly different from that found in the field. Consequently, parents that we identified with resistance to Pythium spp. should be verified in field tests before they are used in a breeding program.

Future work should improve on the assays used for our study. Although a strong, significant correlation was found between assessments observed in the seed rot assay, this was not the case for all root rot assessments. There was a significant correlation between root rot severity and adjusted emergence; however, dry root weight never had a significant correlation with root rot severity. Measuring root length or using wet root weight, rather than dry root weight, may demonstrate a relationship with root rot severity. Additionally, no significant difference was detected for adjusted dry root weight between the parents for any of the species tested. It would be beneficial to use wet root weight, where the weights are not too small to detect differences between parents. Additionally, using a different experimental design, such as a randomized complete block design, or increasing the number of seed tested per replication could reduce variability between assessments, thus lowering the standard error and increasing the ability to detect differences between parents.

The SoyNAM parents proved to be a useful resource for identifying resistance to seedling disease caused by Pythium spp. These data will be used to identify RIL populations from the SoyNAM populations that were developed from these lines. Populations will be subsequently characterized for resistance to identify QTLs contributing to resistance. 


\section{Literature Cited}

Adegbola, M. O. K., and Hagedorn, D. J. 1970. Host resistance and pathogen virulence in Pythium blight of bean. Phytopathology 60:1477-1479.

Allen, T. W., Bradley, C. A., Sisson, A. J., Byamukama, E., Chilvers, M. I., Coker, C. M., Collins, A. A., Damicone, J. P., Dorrance, A. E., Dufault, N. S., Esker, P. D., Faske, T. R., Giesler, L. J., Grybauskas, A. P., Hershman, D. E., Hollier, C. A., Isakeit, T., Jardine, D. J., Kelly, H. M., Kemerait, R. C., Kleczewski, N. M., Koenning, S. R., Kurle, J. E., Malvick, D. K., Markell, S. G., Mehl, H. L., Mueller, D. S., Mueller, J. D., Mulrooney, R. P., Nelson, B. D., Newman, M. A., Osborne, L., Overstreet, C., Padgett, G. B., Phipps, P. M., Price, P. P., Sikora, E. J., Smith, D. L., Sprulock, T. N., Tande, C. A., Tenuta, A. U., Wiese, K. A., and Wrather, J. A. 2017. Soybean yield loss estimates due to diseases in the United States and Ontario, Canada, from 2010 to 2014. Plant Health Prog. 18:19-27.

Avanzato, M. V., and Rupe, J. C. 2011. Role of soybean seed exudates in cultivar resistance to Pythium aphanidermatum. Phytopathology 101 (6S):S11.

Bates, G. D., Rothrock, C. S., and Rupe, J. C. 2008. Resistance of the soybean cultivar Archer to Pythium damping-off and root rot caused by several Pythium spp. Plant Dis. 92:763-766.

Broders, K. D., Lipps, P. E., Paul, P. A., and Dorrance, A. E. 2007. Characterization of Pythium spp. associated with corn and soybean seed and seedling disease in Ohio. Plant Dis. 91:727-735.

De Bruin, J. L., and Pedersen, P. 2008. Soybean seed yield response to planting date and seeding rate in the upper Midwest. Agron. J. 100:696-703.

Diers, B., Specht, J., Hyten, D., Cregan, P., Nelson, R., and Beavis, B. 2011. Soybean Nested Association Mapping. https://soybase.org/meeting_presentations/ soybean_breeders_workshop/SBW_2011/Diers.pdf

Dorrance, A. E., Berry, S. A., Bowen, P., and Lipps, P. E. 2004. Characterization of Pythium spp. from three Ohio fields for pathogenicity on corn and soybean and metalaxyl sensitivity. Plant Health Prog. 5:10.

Dorrance, A. E., Robertson, A. E., Cianzio, S., Giesler, L. J., Grau, C. R., Draper, M. A., Tenuta, A. U., and Anderson, T. R. 2009. Integrated management strategies for Phytophthora sojae combining host resistance and seed treatments. Plant Dis. 93:875-882.

Dorrance, A. E., and Schmitthenner, A. F. 2000. New sources of resistance to Phytophthora sojae in the soybean plant introductions. Plant Dis. 84:1303-1308.

Ellis, M. L., McHale, L. K., Paul, P. A., St. Martin, S. K., and Dorrance, A. E. 2013. Soybean germplasm resistant to Pythium irregulare and molecular mapping of resistance quantitative trait loci derived from the soybean accession PI424354. Crop Sci. 53:1008-1021.

Graham, T. L. 1991. Flavonoid and isoflavonoid distribution in developing soybean seedling tissues and in seed and root exudates. Plant Physiol. 95: 594-603.

Griffith, D. R., Mannering, J. V., and Moldenhauer, W. C. 1977. Conservation tillage in the eastern corn belt. J. Soil Water Conserv. 32:20-28.

Johnson, L. F., and Palmer, G. K. 1985. Symptom variability and selection for reduced severity of cotton seedling disease caused by Pythium ultimum. Plant Dis. 69:298-300.

Kirkpatrick, M. T., Rothrock, C. S., Rupe, J. C., and Gbur, E. E. 2006. The effect of Pythium ultimum and soil flooding on two soybean cultivars. Plant Dis. 90: 597-602.

Kulkarni, R. N., and Baskaran, K. 2003. Inheritance of resistance to Pythium dieback in the medicinal plant periwinkle. Plant Breed. 122:184-187.

Mahuku, G. S., Buruchara, R. A., and Navia, M. 2005. A gene that confers resistance to Pythium root rot in common bean: genetic characterization and molecular markers. Phytopathology 95:S64.

Matthiesen, R. L., Ahmad, A. A., and Robertson, A. E. 2016. Temperature affects aggressiveness and fungicide sensitivity of four Pythium spp. that cause soybean and corn damping-off in Iowa. Plant Dis. 100:583-591.

Murillo-Williams, A., and Pedersen, P. 2008. Early incidence of soybean seedling pathogens in Iowa. Agron. J. 100:1481-1487.
Ohh, S. H., King, T. H., and Kommedahl, T. 1978. Evaluating peas for resistance to damping-off and root rot caused by Pythium ultimum. Phytopathology 68: 1644-1649.

Pieczarka, D. J., and Abawi, G. S. 1978. Effect of interaction between Fusarium, Pythium, and Rhizoctonia on severity of bean root rot. Phytopathology 68: 403-408.

Rizvi, S. S. A., and Yang, X. B. 1996. Fungi associated with soybean seedling disease in Iowa. Plant Dis. 80:57-60.

Rod, K. S., Walker, D. R., and Bradley, C. A. 2018. Evaluation of major ancestors of North American soybean cultivars for resistance to three Pythium species that cause seedling blight. Plant Dis. 102:2241-2252.

Rojas, J. A., Jacobs, J., Napieralski, S., Karaj, B., Bradley, C. A., Chase, T., Esker, P., Giesler, L., Jardine, D., Malvick, D., Markell, S., Nelson, B., Robertson, A., Rupe, J., Smith, D., Sweets, L., Tenuta, A., Wise, K., and Chilvers, M. 2017b. Oomycete species associated with soybean seedlings in North America-Part II: diversity and ecology in relation to environmental and edaphic factors. Phytopathology 107:293-304.

Rojas, J. A., Jacobs, J. L., Napieralski, S., Karaj, B., Bradley, C. A., Chase, T., Esker, P. D., Giesler, L. J., Jardine, D. J., Malvick, D. K., Markell, S. G., Nelson, B. D., Robertson, A. E., Rupe, J. C., Smith, D. L., Sweets, L. E., Tenuta, A. U., Wise, K. A., and Chilvers, M. I. 2017a. Oomycete species associated with soybean seedlings in North America-Part I: identification and pathogenicity characterization. Phytopathology 107:280-292.

Rosso, M. L., Rupe, J. C., Chen, P., and Mozzoni, L. A. 2008. Inheritance and genetic mapping of resistance to Pythium damping-off caused by Pythium aphanidermatum in 'Archer' soybean. Crop Sci. 48:2215-2222.

Scott, K., Balk, C., Veney, D., McHale, L. K., and Dorrance, A. E. 2019. Quantitative disease resistance loci towards Phytophthora sojae and three species of Pythium in six soybean nested association mapping populations. Crop Sci. 59:605-623.

Stewart, S. M. 2011. Characterization and management of genetic diversity in Phytophthora sojae populations (Doctoral dissertation). Iowa State University Digital Repository.

Thomson, T. B., Athow, K. L., and Laviolette, F. A. 1971. The effect of temperature on the pathogenicity of Pythium aphanidermatum, P. debaryanum, and $P$. ultimum. Phytopathology 68:403-408.

Van Doren, D. M., Jr., and Triplett, G. B., Jr. 1973. Mulch and tillage relationships in corn culture. Soil Sci. Soc. Am. Proc. 37:766-769.

Wickramasinghe, D., Acharya, B., Plewa, D., and Dorrance, A. E. 2012. Screening for resistance to Phytophthora sojae, Fusarium graminearum, and Pythium irregulare in nested association mapping (NAM) populations. APS North Central Division 2012 Meeting, Ohio.

Wrather, J. A., and Koenning, S. R. 2006. Estimates of disease effects on soybean yields in the United States 2003 to 2005. J. Nematol. 38:173-180.

Wrather, J. A., and Koenning, S. R. 2009. Effects of diseases on soybean yields in the United States 1996 to 2007. Plant Health Prog. 10:24.

Yang, D. E., Jin, D. M., Wang, B., Zhang, D. S., Nguyen, H.-T., Zhang, C. L., and Chen, S. J. 2005. Characterization and mapping of Rpil, a gene that confers dominant resistance to stalk rot in maize. Mol. Genet. Genomics 274:229-234.

Yang, X. B. 1999. Pythium damping-off and root rot. Pages $42-44$ in: Compendium of Soybean Diseases, 4th ed. G. L. Hartman, J. B. Sinclair, and J. C. Rupe, eds. American Phytopathological Society Press, St. Paul, MN.

Yang, X. B., and Feng, F. 2001. Ranges and diversity of soybean fungal diseases in North America. Phytopathology 91:769-775.

Zhang, B. Q., and Yang, X. B. 2000. Pathogenicity of Pythium populations from corn-soybean rotation fields. Plant Dis. 84:94-99.

Zhang, J. X., Xue, A. G., Cober, E. R., Morrison, M. J., Zhang, H. J., Zhang, S. Z., and Gregorich, E. 2013. Prevalence, pathogenicity, and cultivar resistance of Fusarium and Rhizoctonia species causing soybean root rot. Can. J. Plant Sci. 93:221-236. 